\title{
Enhanced photoelectrochemical water-splitting performance of semiconductors by surface
} Cite this: Energy Environ. Sci., 2014, 7, passivation layers
2504

\author{
Rui Liu, ${ }^{a}$ Zhi Zheng, ${ }^{\text {bc }}$ Joshua Spurgeon ${ }^{\mathrm{a}}$ and Xiaogang Yang ${ }^{\star b c}$
}

An important approach for solving the world's sustainable energy challenges is the conversion of solar energy to chemical fuels. Semiconductors can be used to convert/store solar energy to chemical bonds in an energy-dense fuel. Photoelectrochemical (PEC) water-splitting cells, with semiconductor electrodes, use sunlight and water to generate hydrogen. Herein, recent studies on improving the efficiency of semiconductor-based solar water-splitting devices by the introduction of surface passivation layers are reviewed. We show that passivation layers have been used as an effective strategy to improve the charge-separation and transfer processes across semiconductor-liquid interfaces, and thereby increase overall solar energy conversion efficiencies. We also summarize the demonstrated passivation effects brought by these thin layers, which include reducing charge recombination at surface states, increasing the reaction kinetics, and protecting the semiconductor from chemical corrosion.

Received 8th February 2014

Accepted 30th May 2014

DOI: $10.1039 / \mathrm{c} 4 \mathrm{ee} 00450 \mathrm{~g}$

www.rsc.org/ees

These benefits of passivation layers play a crucial role in achieving highly efficient water-splitting devices in the near future.

\begin{abstract}
Broader context
Semiconductor interface is one of the most important components/regions in photoelectrochemical (PEC) water splitting devices. The serious surface charge recombination, slow charge transfer kinetics and the poor photoelectrochemical stability are the three main challenges for the practical PEC water splitting devices. Recently, the studies of constructing passivation layer onto the semiconductor to address these challenges have attracted increasing research attentions, due to the potential application of solar to chemical energy conversion. When these layers incorporated onto semiconductor surface, significant changes of the interface would be found including charge transfer improvement, surface charge recombination, and chemical corrosion, etc. Although various strategies have been suggested for this surface modification, a synergetic effect must be achieved on an advanced photoelectrodes accounting for the improved solar-tohydrogen efficiencies. This review will shed light on the recent PEC water splitting work surface state passivation, corrosion retardation and charge transfer improvement in this passivation layer.
\end{abstract}

\section{Introduction}

Modern Society relies on a steady, dependable supply of energy. Currently, approximately $85 \%$ of the global primary energy need is met by burning fossil fuels. ${ }^{1,2}$ However, depletion of this nonrenewable resource and build-up of carbon dioxide in the atmosphere are well-known global challenges. To address these issues, renewable energy systems are needed. In particular, solar energy stands out as a widely distributed, abundant, clean energy source and has therefore attracted intense attention for many years. ${ }^{3-7}$ However, solar light is also diffuse, diurnal, and intermittent, which hampers its direct use in many

aJoint Center for Artificial Photosynthesis, California Institute of Technology, Division of Chemistry and Chemical Engineering, Pasadena, CA 91125, USA

${ }^{b}$ Key Laboratory of Micro-Nano Materials for Energy Storage, Conversion of Henan Province, Henan 461000, China.E-mail: xiaogang.yang@gmail.com

'Institute of Surface Micro and Nano Materials, Xuchang University, Henan 461000, China applications. To better utilize the solar resource, technologies that can efficiently and inexpensively store solar energy for offhour use are needed. ${ }^{6}$ The use of photoectrochemical (PEC) cells to produce fuels from sunlight, water $\left(\mathrm{H}_{2}\right.$ via water-splitting) and $\mathrm{CO}_{2}$ (hydrocarbons) is a promising approach to address this energy challenge..$^{3,8}$

One method to achieve solar water-splitting employs photoactive semiconductors in a photoelectrochemical cell, ${ }^{9}$ which has three main components: an anode, a cathode, and an electrolyte. Water oxidation occurs at the anode through the oxygen evolution reaction (OER), while hydrogen forms reductively at the cathode through the hydrogen evolution reaction (HER). ${ }^{10}$ At least one of the electrodes needs to be a photoactive semiconductor that absorbs light to produce electrons and holes and generates the photovoltage needed to split water. Although most PEC water-splitting devices reported to date have suffered from low solar-to-hydrogen efficiency, studies indicate that theoretical efficiencies as high as $30 \%{ }^{8}$ for a single semiconductor light absorber with a band gap of $1.6 \mathrm{eV}$ at 1 Sun are 
possible. ${ }^{\mathbf{4 1 1 - 1 3}}$ Thus the primary focus of researchers in this field is to engineer materials for more efficient solar energy conversion to chemical fuel.

Some commonly used strategies to improve the overall solarto-hydrogen efficiency in PEC devices include: (1) increasing the photocurrent by engineering the semiconductor absorber layer morphology to yield better light absorption; ${ }^{\mathbf{1 4 - 2 2}}$ (2) improving charge-carrier transfer and collection efficiency by micro- or nanostructuring the semiconductor; ${ }^{19,23-25}$ (3) lowering the reaction overpotential and improving the heterogeneous reaction kinetics by attaching catalysts to the surface of the anode and/or cathode; ${ }^{26-28}$ (4) application of a surface dipole layer on the semiconductor to shift the relative positions of the valence and conduction bands relative to the HER and OER reactions in the electrolyte; ${ }^{29}$ (5) improving charge separation by use of a surface layer to create a buried $\mathrm{p}-\mathrm{n}$ junction to achieve a higher

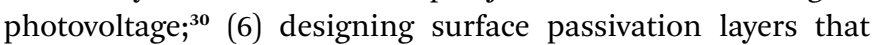
chemically or physically protect the semiconductor from corrosion $^{31}$ and (7) reducing the rate of electron-hole recombination by surface state passivation ${ }^{32}$ or by surface catalyst layers. ${ }^{33}$

Passivation layers were originally applied to semiconductor photoelectrodes to reduce corrosion and improve their chemical or photochemical stability when immersed in an electrolyte. ${ }^{34-36}$ However, surface layers can also be used to prevent formation of band gap states that promote electron-hole recombination, can catalyze the water splitting reactions at the semiconductor-electrolyte interface,$^{26,37,38}$ and often contribute to shifts in the band positions of the semiconductor relative to the solution by their charge distributions. ${ }^{29,39,40}$ A passivation layer in this review is used to denote any surface layer that suppresses the competitive consumption of photogenerated charge by side reactions and thereby increases the overall PEC performance of the water splitting reaction, including the Faradaic efficiencies and photovoltage.

Studies have shown that even a very thin layer on the photoelectrodes can alter the surface properties..$^{31,32,41-45}$ In particular, the rational design of passivation layers for photoelectrodes has attracted much interest recently due to the following advantages of this strategy:

(a) Passivation layers can improve the efficiency of PEC cells by the inhibition of deleterious reactions and catalyzing beneficial ones (see 1-7 above).

(b) Passivation layers can be very thin (typically $<100 \mathrm{~nm}$, often only 1-2 $\mathrm{nm}$ ) thus preventing parasitic light absorption or charge-transfer inhibition.

(c) Passivation layers can be fabricated by atomic layer deposition (ALD), ${ }^{\mathbf{4}}$ spin coating, ${ }^{47}$ electrochemical deposition, ${ }^{26,44}$ sputtering, ${ }^{48}$ electron beam evaporation, ${ }^{48}$ and floating transfer ${ }^{49}$ or dip casting. ${ }^{50,51}$

(d) Passivation layers can readily be incorporated onto high surface area or high aspect ratio nanostructures. ${ }^{22,27}$

In this review, we focus on recent developments with passivation layers to improve the overall water-splitting efficiency of both photocathodes and photoanodes (interested readers are referred to the general reviews of solar PEC watersplitting by Walter et $a .^{8}$ and by Li et $a l .{ }^{52}$ ). We focus on three main benefits of using inorganic passivation layers on photoelectrodes: the suppression of surface recombination, the improved reaction kinetics at catalytic layers, the chemical or physical protection against corrosion, and the use of buried semiconductor junctions. Examples that combine these effects in a single system are also reviewed.

\section{Passivation layer suppression of surface recombination and improvement of reaction kinetics}

Work by Seger et al. ${ }^{28}$ and others ${ }^{53-55}$ has shown that higher charge-collection efficiency in photovoltaics can be achieved with single crystal semiconductors compared to polycrystalline material due to reduced recombination as a result of fewer grain boundaries and surface defects. This finding extends to PEC water-splitting, which also involves the separation of photogenerated charges in semiconductors under illumination. ${ }^{56,57}$ However, because of the high fabrication cost, single crystal photoelectrodes are less practical in largescale solar energy applications. Polycrystalline photoelectrode devices have been extensively studied as a more cost-effective alternative approach. The surface state density of polycrystalline semiconductors, however, is much higher than in single crystal materials, which decreases performance due to greater surface recombination of the photogenerated charges. Mitigation of this deleterious charge recombination with a surface passivation layer is thus a promising approach to achieve greater efficiencies in polycrystalline semiconductors.

In a typical PEC water splitting-system, using photoanodes as an example, the anodic onset or turn-on potential (i.e., the voltage where anodic current is first experimentally observed), $V_{\text {on,A }}$ relative to a reference electrode, relates to the photovoltage $\left(V_{\mathrm{ph}}\right)$, redox pair potential $\left(E\left(\mathrm{~A} / \mathrm{A}^{-}\right)\right)$and kinetic overpotential $(\eta)$ as in eqn (1): ${ }^{58}$

$$
\begin{gathered}
V_{\mathrm{on}, \mathrm{A}}=E\left(\mathrm{~A} / \mathrm{A}^{-}\right)-\left(V_{\mathrm{ph}}\right)+\eta=E\left(\mathrm{~A} / \mathrm{A}^{-}\right)-\left(V_{\mathrm{ph}}-\eta\right) \\
\Delta V \equiv E\left(\mathrm{~A} / \mathrm{A}^{-}\right)-V_{\mathrm{on}, \mathrm{A}}=\left(V_{\mathrm{ph}}-\eta\right)
\end{gathered}
$$

In eqn (1), for a fixed redox pair potential, $E\left(\mathrm{~A} / \mathrm{A}^{-}\right)$, the onset potential is a balance between the photovoltage and the overpotential, and is an important metric in photoelectrochemical energy-conversion performance. The voltage change, $\Delta V$, in eqn (2), is analogous to the open-circuit voltage in solid-state photovoltaics, which is comparable to a photovoltage without kinetic overpotential losses, $V_{\mathrm{ph}}$.

The introduction of a surface layer changes the semiconductor surface environment and can modulate the performance, including a shift in the onset potential $\left(\Delta V_{\text {on }}\right)$, as shown in Table 1 for several literature examples. By either reducing the catalytic overpotential or reducing the surface recombination, a passivation layer can increase the photovoltage, leading to a cathodic shift of the onset potential in the case of a photoanode (Fig. 1a). ${ }^{26,32,41,42,59,60}$ 
Likewise, a similar anodic shift in onset potential would benefit photocathodes, expressed as eqn (3), where the anodic shift of $V_{\text {on,C }}$ should be observed when a passivation layer is applied on the electrode surface.

$$
V_{\mathrm{on}, \mathrm{C}}=E\left(\mathrm{~A} / \mathrm{A}^{-}\right)+\left(V_{\mathrm{ph}}-\eta\right)
$$

The photovoltage $\left(V_{\mathrm{ph}}\right)$, generated by the semiconductor, significantly influences the turn on voltage. From eqn (1) and (3), during photoreaction with current flow, this shift $\left(\Delta V_{\text {on }}\right)$ represents the difference of apparent photovoltage $\left(V_{\mathrm{ph}}-\eta\right)$. The comparison between the $V_{\text {on }}$ would exhibit the apparent photovoltage in the literature (see Table 1).

Metal oxide semiconductors have been widely studied as photoanodes due to their band gap and positive valence band edge. Hematite $\left(\alpha-\mathrm{Fe}_{2} \mathrm{O}_{3}\right)$ is an attractive material as a photoanode in PEC water-splitting due to its ability to absorb light across much of the visible spectrum (band gap $\sim 2.1 \mathrm{eV}$ ), high photoelectrochemical stability in alkaline solution, and earth abundance. ${ }^{59}$ The main drawbacks of hematite include a high density of surface states, low mobility of holes, a short hole lifetime, and slow kinetics for the oxygen evolution reaction (OER) at its surface. Bisquert's group showed how the surface state trap density of n-type hematite varied with potential and that these states preferentially trap holes before they reach the electrolyte and oxidize water (Fig. 2a). ${ }^{68}$ Therefore, researchers have applied various materials as trap-state passivation layers on hematite to improve the photoanodic performance of the OER reaction (Fig. 2b)..$^{32}$ (a)

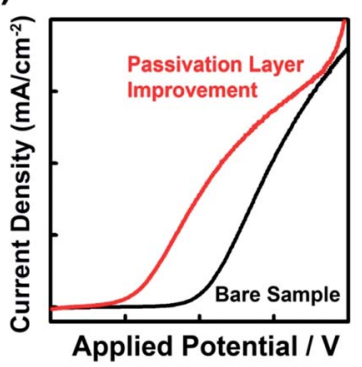

(c)

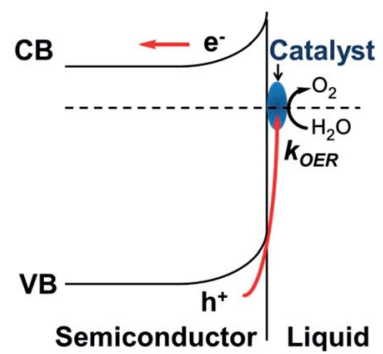

(b)

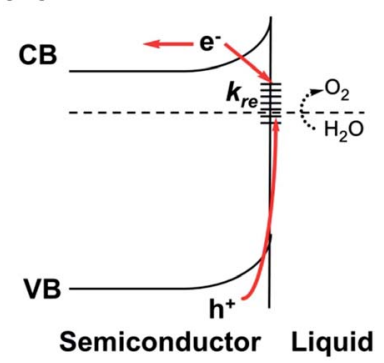

(d) Passivation Layer

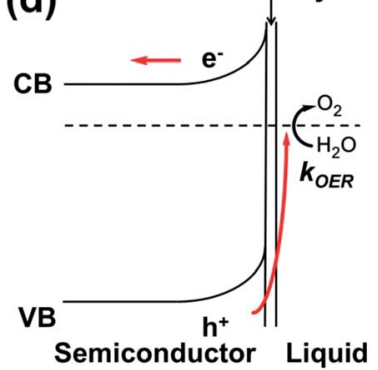

Fig. 1 Comparison of an n-type semiconductor photoanode and the effect on surface states with/without a passivation layer in a water-splitting PEC cell: (a) the schematic J-V curves of an photoanode with (red trace) and without (black trace) (a) surface passivation layer; (b) surface defect states in the band structure, which lead to high charge recombination and inefficient water oxidation by the photogenerated holes; (c) application of an OER catalyst layer, which promotes facile hole transfer across the interface to the catalyst for improving water oxidation; (d) application of a thin noncatalytic surface layer to passivate defect states, strongly suppressing surface recombination for improving water oxidation.

Table 1 Comparison of PEC water-splitting performance with passivation layers

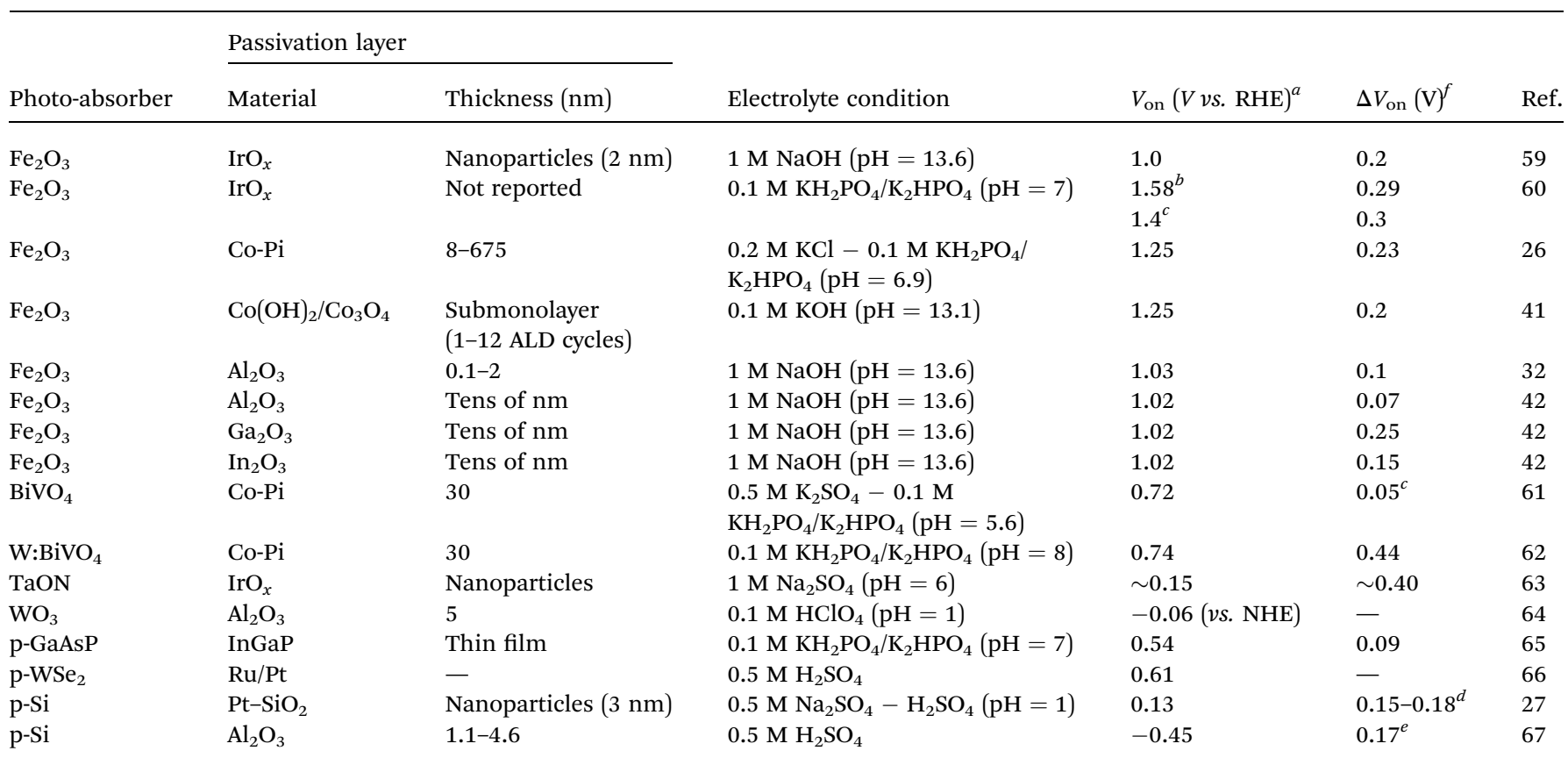

${ }^{a}$ RHE: reversible hydrogen electrode, all potentials in this review are $v s$. RHE, unless specified otherwise. ${ }^{b}$ Potential at photocurrent of $200 \mu \mathrm{A}$ $\mathrm{cm}^{-2}$. ${ }^{c}$ Potential read at the photocurrent of $20 \mu \mathrm{A} \mathrm{cm}{ }^{-2}$ from figures. ${ }^{d}$ Potential at the photocurrent of $1 \mathrm{~mA} \mathrm{~cm}^{-2}$. ${ }^{e}$ Potential at the photocurrent of $15 \mathrm{~mA} \mathrm{~cm}{ }^{-2} .{ }^{f}$ Cathodic onset potential shift of photoanode: $\Delta V_{\text {on }}=\mid V_{\text {on }}($ bare $)-V_{\text {on }}($ passivated $) \mid$. 

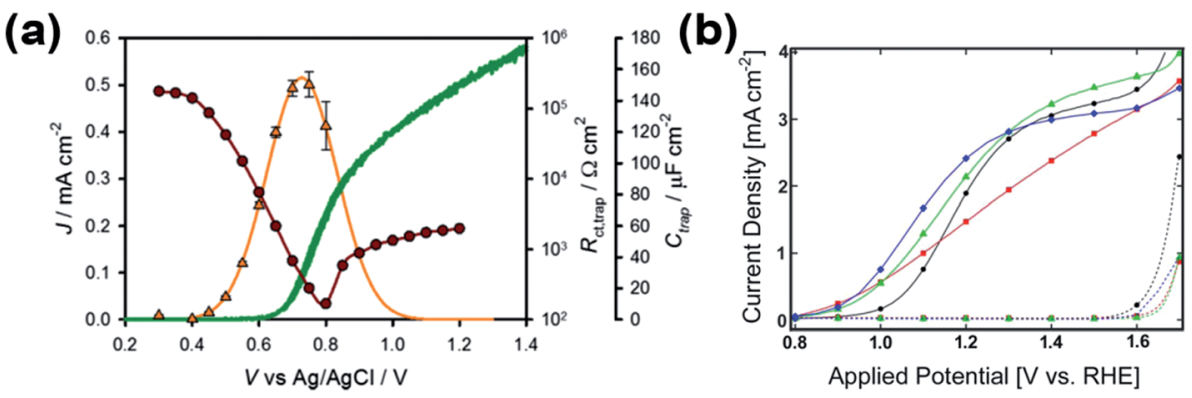

Fig. 2 (a) $J-V$ curve (green solid line) and $C_{\text {trap }}$ (orange triangles) and $R_{\mathrm{ct} \text {,trap }}$ (red circles) values obtained for a $60 \mathrm{~nm}$ hematite electrode under 1 sun illumination and pH 6.9, adopted from literature, reprinted with permission from ref. 68, copyright (2012) American Chemical Society. (b) J-V curves of the hematite photoanode passivated with $1 \mathrm{ALD}$ cycle of $\mathrm{Al}_{2} \mathrm{O}_{3}$ measured after deposition (red squares), after annealing for 20 min at $300^{\circ} \mathrm{C}$ (green triangles) and after annealing for $20 \mathrm{~min}$ at $400{ }^{\circ} \mathrm{C}$ (blue diamonds) are compared to a control, which is the same sample before ALD (black circles). Reproduced from ref. 32 with permission from The Royal Society of Chemistry.

Monoclinic $\mathrm{BiVO}_{4}$ is also an n-type semiconductor with a band gap of $2.4 \mathrm{eV}$ that has been widely studied as a photoanode material..$^{52}$ Its main problems have been photocorrosion and insufficient photovoltage, due to the high surface recombination of the photogenerated charges from surface defect states and/or poor interfacial kinetics.

Both a high density of surface defect (trap) states and slow charge transfer kinetics can contribute to charge recombination at the surface. The competition between charge recombination and the kinetics of the heterogeneous charge transfer to the solution redox pair has a strong dependence on the minoritycarrier concentration at the solid-liquid interface (Fig. 1b). Thin surface layers can passivate surface charge recombination by preventing formation of the surface defect states and/or promote the desired chemical reaction by catalyzing faster charge transfer to the redox species. Both surface treatment mechanisms enhance quantum efficiency for the water-splitting reaction, by reducing the charge-carrier losses at the interface.

Relative to a bare semiconductor, catalyst layers can provide an alternative route for minority-carriers at the interface. The increased rate of charge transfer from the surface (catalyst) to the redox pair in solution reduces the overpotential needed to drive the PEC reaction. This leads to a lower charge-carrier surface density than for a bare semiconductor. Iridium oxide, cobalt phosphate, and cobalt oxide are some of the OER catalysts that have been applied as passivation layers on hematite. Tilley et al. used a layer of $\mathrm{IrO}_{2}$ nanoparticles ( $\sim 2 \mathrm{~nm}$ diameter) on hematite photoanodes by electrodeposition, resulting in a cathodic shift in the onset potential from $1.0 \mathrm{~V}$ to $0.8 \mathrm{~V} v s$. RHE. ${ }^{59}$ Riha et al. reported that cobalt oxide monolayers and partial monolayers were successfully coated on hematite photoanodes by an atomic layer deposition method. ${ }^{41} \mathrm{~A}$ stable 100 $\mathrm{mV}$ cathodic shift in onset potential was achieved on the planar device, and an even higher cathodic shift of $\sim 200 \mathrm{mV}$ was obtained on an inverse opal hematite scaffold. Impedance measurements showed that the charge transfer resistance at the $\mathrm{Fe}_{2} \mathrm{O}_{3} / \mathrm{H}_{2} \mathrm{O}$ interface was reduced by an order of magnitude, suggesting catalytic behavior of the cobalt oxide passivation layer.

The surface charge transfer kinetics can be significantly improved by applying catalyst on the top surface (Fig. 1c). For instance, $\mathrm{IrO}_{x}$ electrodeposited on hematite films showed a $\sim 300 \mathrm{mV}$ cathodic shift in $V_{\mathrm{On}, \mathrm{A}}{ }^{60}$ and a thick cobalt phosphate (Co-Pi) catalyst photoelectrodeposited on hematite cathodically shifted $V_{\text {on }, \mathrm{A}}$ by $\sim 230 \mathrm{mV}{ }^{26}$ Transient photocurrent and chopped-light measurements showed that the valence band holes in hematite efficiently oxidized $\mathrm{Co}(\mathrm{III})$ in Co-Pi films to $\mathrm{Co}(\mathrm{IV})$ in the catalyst layer. By using impedance spectroscopy measurements, water oxidation was proposed to predominately arise from the Co-Pi film instead of the hematite surface. Hamann et al. reported the capacitive nature (Fig. 3a and b) of the "Co-Pi" catalyst resulted in a change of the charge transport pathway for water oxidation and decrease surface charge recombination as measured with impedance and transient photocurrent spectroscopies. ${ }^{26}$ In these two cases, the $\mathrm{IrO}_{x}$ and Co-Pi catalyst layers increased the charge transfer rate. Similar catalytic results were reported by Abe et al., where the $V_{\text {on,A }}$ had a cathodic shift of $0.4 \mathrm{~V}$ on an $\mathrm{IrO}_{x}$ nanoparticle-coated TaON photoanode compared to a bare electrode. ${ }^{63}$ These layers accumulated the photogenerated holes from semiconductors for the generation of one oxygen molecule by four holes. Thus this process reduced interfacial charge recombination, and improved OER reaction kinetics. Similarly, Co-Pi on bare $\mathrm{BiVO}_{4}$ led to a $50 \mathrm{mV}$ cathodic shift in onset potential, ${ }^{61}$ and a Co-Pi modified W: $\mathrm{BiVO}_{4}$ photoanode yielded a large cathodic shift of $440 \mathrm{mV} .^{62}$ In each of these examples, the catalyst layer facilitates improved charge transfer at the interface (Fig. 1c).

Alternatively, other groups have proposed a different interpretation of the catalytic mechanism leading to an improved onset potential. For example, transient absorption study showed the PEC performance improvement of $\mathrm{CoO}_{x}$ deposition on hematite film is due to the formation of a Schottky-type heterojunction. ${ }^{33}$ The increased band bending benefitted charge separation in the hematite, and the charge recombination was strongly inhibited due to the reduced electron density on the surface. Later, Barroso, Durrant et al. deduced from the observed increase in the hole lifetime, observed by transient absorption spectroscopy, that the "Co-Pi" layer was a "spectator" only increasing the hole concentration in the hematite rather than acting as a catalyst. ${ }^{37,69} \mathrm{~A} \mathrm{Ga}_{2} \mathrm{O}_{3}$ layer on hematite showed an increase in hole concentration similar to that of "CoPi" (Fig. 3c and d). Different from this, $\mathrm{Ga}_{2} \mathrm{O}_{3}$ was considered as 

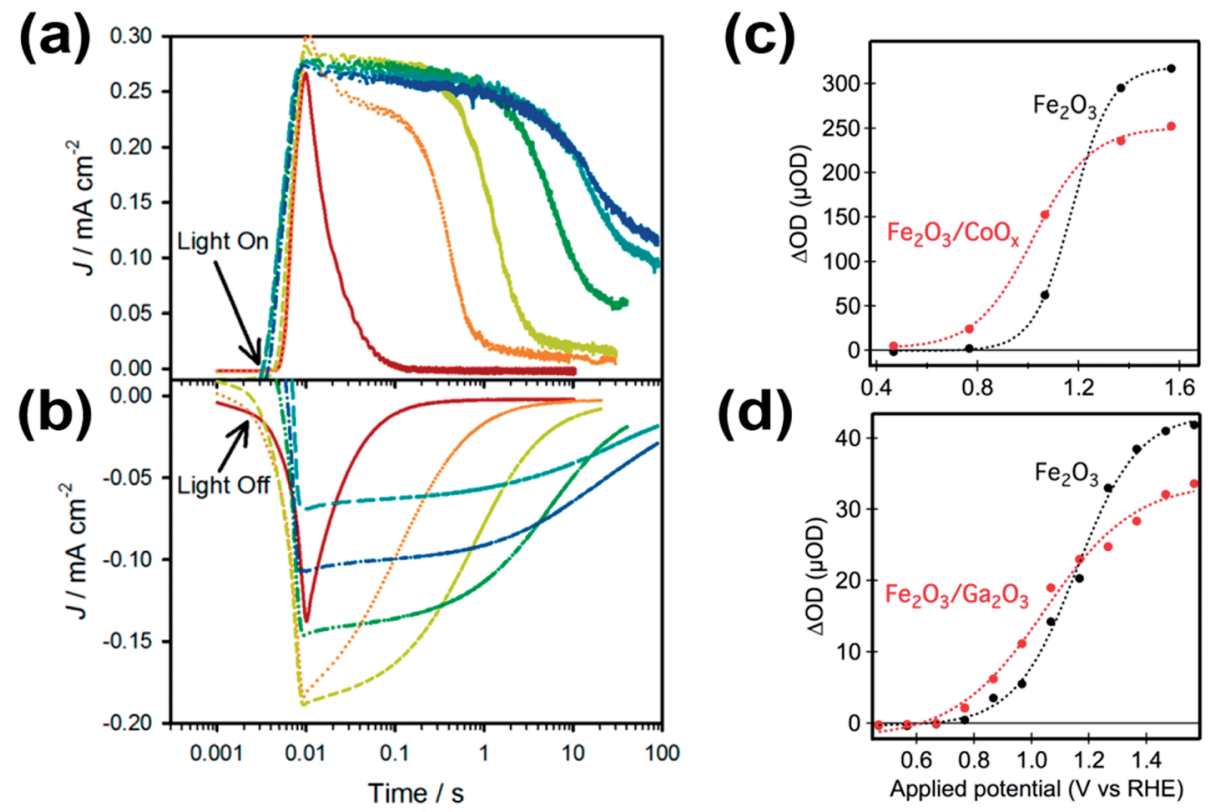

Fig. 3 (a) Anodic and (b) cathodic transients measured for a bare hematite electrode (red solid line) and the same electrode with Co-Pi catalyst in contact with a pH 6.9 buffered aqueous solution under 1 sun illumination at an applied bias of $1.05 \mathrm{~V}$ vs. RHE: 1 (orange dotted line), 2 (yellow short dashed line), 15 (green dashed double dotted line), 45 (teal long dashed line) and 90 (blue dashed single dotted line) $\mathrm{mC} \mathrm{cm}^{-2} \mathrm{Co}-\mathrm{Pi}$ catalyst on hematite. Reprinted with permission from ref. 26, copyright (2012) American Chemical Society. (c) Amplitude of the $700 \mathrm{~nm}$ transient absorption measured at 50 ms after laser excitation, as a function of applied bias, for APCVD hematite before and after surface modification with $\mathrm{CoO}_{x}$ and (d) for ultrathin USP hematite before and after surface modification with $\mathrm{Ga}_{2} \mathrm{O}_{3}$. The dotted lines are intended to guide the eye and are not fits to a specific model, ${ }^{69}$ Copyright (2012) National Academy of Sciences, USA.

a surface state passivation layer on hematite by Sivula et al. ${ }^{\mathbf{4 2}}$ Comparing the rate constants for recombination and hole transfer during OER at hematite photoanodes by intensitymodulated photocurrent spectroscopy, Cummings et al. found that the surface treatment by a Co(II) solution did not accelerate hole transfer but suppressed surface charge recombination. ${ }^{70}$

Noncatalytic oxide layers on hematite have also been shown to affect the OER behavior at the surface, even though no catalytic sites exist to enhance the charge transfer process (Fig. 1d). Formal et al. reported that an ultrathin ALD coating of $\mathrm{Al}_{2} \mathrm{O}_{3}$ on hematite improved the $V_{\text {on, } \mathrm{A}}$ by as much as $100 \mathrm{mV}$, where a significant change in the surface capacitance and onset potential suggest passivation of the surface states. ${ }^{32}$ Hisatomi et al. used $\mathrm{Al}_{2} \mathrm{O}_{3}, \mathrm{Ga}_{2} \mathrm{O}_{3}$, and $\operatorname{In}_{2} \mathrm{O}_{3}$ overlayers on thin hematite films (27-30 nm) through a chemical bath deposition, which led to a cathodic shift in $V_{\text {on,A }}$ of $70 \mathrm{mV}, 250 \mathrm{mV}$ and $150 \mathrm{mV}$, respectively, compared to the bare hematite. The photogenerated holes had longer lifetimes with these overlayers than those remaining in hematite due to the reduced defects and lower electron concentration. The similar crystal structure of materials like corundum-type $\mathrm{Ga}_{2} \mathrm{O}_{3}$ to hematite could reduce the lattice strain and decrease the density of surface state defects. ${ }^{42}$ Interestingly, when $\mathrm{TiO}_{2}$ was deposited on hematite by ALD, the current density decreased for the photooxidation of water with an increased number of ALD cycles. ${ }^{32}$ The performance was still poorer than the bare hematite samples after a thermal annealing at 300 and $400{ }^{\circ} \mathrm{C}$. $\mathrm{TiO}_{2}$ has a band gap similar to the corundum-type oxides above, so the reason for the decreased performance was not clear. This result indicated that the material and crystal phase may have a significant impact on the layer's ability to reduce surface states.

Kim et al. recently applied a $5 \mathrm{~nm} \mathrm{Al} \mathrm{A}_{2} \mathrm{O}_{3}$ layer by $\mathrm{ALD}$ on $\mathrm{WO}_{3}$ photoanodes to passivate the surface states, which displayed a 3-fold photocurrent and Faradaic efficiency enhancement in 0.1 M $\mathrm{HClO}_{4}$ solution $(\mathrm{pH}=1) .{ }^{64}$ Their laser flash photolysis measurements of $\mathrm{WO}_{3}$ and $\mathrm{Al}_{2} \mathrm{O}_{3} / \mathrm{WO}_{3}$ thin films showed the electron trapping decreased in the presence of an alumina overlayer whereas hole trapping increased with alumina. The onset potential had little cathodic shift with $\mathrm{Al}_{2} \mathrm{O}_{3}$ passivation, different from $\mathrm{Al}_{2} \mathrm{O}_{3} / \mathrm{Fe}_{2} \mathrm{O}_{3}$, indicating that the passivation effect is dependent on the substrate material.

Besides the most widely discussed photoanode materials, surface layers showed similar contribution to PEC performance on photocathodes with high surface charge recombination rates. For example, $\mathrm{Wu}$ et al., fabricated a $\mathrm{p}-\mathrm{n}$ homojunction of GaAsP core-shell nanowires photocathode. A thin layer of InGaP passivated the surface states on GaAsP as confirmed by the enhanced photoluminescence of the nanowires. When Pt was added as an HER catalyst, a $0.09 \mathrm{~V}$ anodic shift of $V_{\text {on }}$ was obtained on an InGaP passivated electrode in 0.1 M KPi buffer solution. ${ }^{65}$ In another case, ${ }^{66}$ by photoelectrochemically depositing $\mathrm{Ru} / \mathrm{Pt} \mathrm{HER}$ catalyst onto a $\mathrm{WSe}_{2}$ surface, J. Mckone et al., showed that recombination at the step edges could be remarkably retarded and the photocurrent was $22.1 \mathrm{~mA} \mathrm{~cm}^{-2}$ at $0 \mathrm{~V}$ (vs. RHE), with $V_{\text {on,C }}$ of $0.610 \mathrm{~V} v s$. RHE. The improvement is dramatic in this case since no noticeable photocurrent was observed for the bare $\mathrm{WSe}_{2}$. Dai et al., used ALD deposition of 3 $\mathrm{nm}$ Pt electrocatalyst on p-Si nanowires, resulting in a $0.15-0.18$ 
$\mathrm{V}$ anodic shift (measured at $1 \mathrm{~mA} \mathrm{~cm}^{-2}$ ) of the $J-V$ curve on the obtained $\mathrm{Pt}-\mathrm{SiO}_{2} / \mathrm{p}$-Si photocathodes, where the in situ formed $\mathrm{SiO}_{2}$ was regarded as a surface-state passivation layer. ${ }^{48} \mathrm{~A}$ similar surface-state passivation effect caused an anodic shift (0.17 $\mathrm{V}$ at $15 \mathrm{~mA} \mathrm{~cm}{ }^{-2}$ ) on $\mathrm{Al}_{2} \mathrm{O}_{3} / \mathrm{p}$-Si planar electrodes.

Thus, numerous works have utilized surface treatments at the semiconductor/liquid interface to improve the solar watersplitting performance of photoelectrodes by reducing the density of surface defect states and/or enhancing the interfacial charge transfer rate to suppress surface recombination. The original idea for the decoration of the semiconductor with OER or HER electrocatalyst was to attain the goal. However, while the approach is widely used, a straightforward application has not always proven successful. For example, when a thin layer of manganese oxide, an OER electrocatalyst, was deposited on hematite by ALD, the catalyst-semiconductor system did not show any synergetic benefits even though the charge-transfer resistance significantly decreased. ${ }^{58}$ The $\mathrm{MnO}_{x}$-decorated photoelectrodes exhibited a significant anodic onset potential shift compared to bare hematite (Fig. 4a). This phenomenon has been understood as a Fermi-level pinning effect, ${ }^{71}$ in which an increased surface-state density due to the introduction of the $\mathrm{MnO}_{x}$ layer led to a substantial reduction in photovoltage generated by the hematite photoanode. Under this condition, the applied bias to the electrode does not induce band bending in the semiconductor, but rather causes a reduction in the charge in the Fermi level pinning surface states. ${ }^{38}$ The potential drop then takes place in the Helmholtz layer instead of the space charge region (as the black and gray lines indicated in Fig. 4b).

This is consistent with the early conclusion by Bard et al., that the surface electronic states can store charge and alter the potential drop across the Helmholtz layer. ${ }^{71}$ In an ideal photoanode system (Fig. 4c), foreign material on the semiconductor surface influences the charge transfer at the solid-liquid interface leading to a reduced overpotential. On the other hand, surface defect states can be passivated or generated at the interface between the semiconductor and this surface layer. (a)

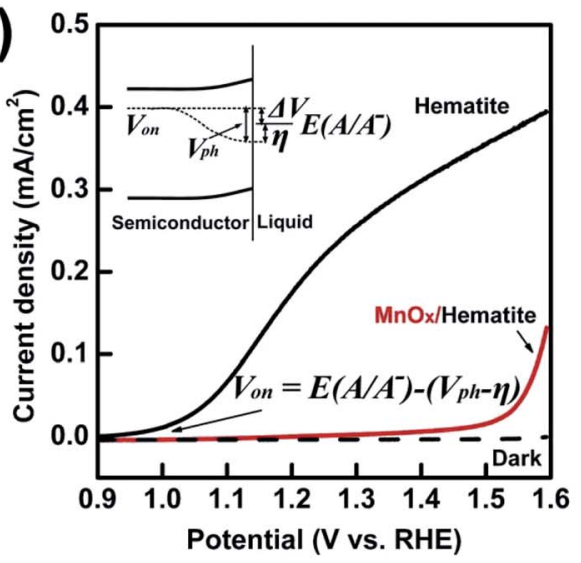

(b)

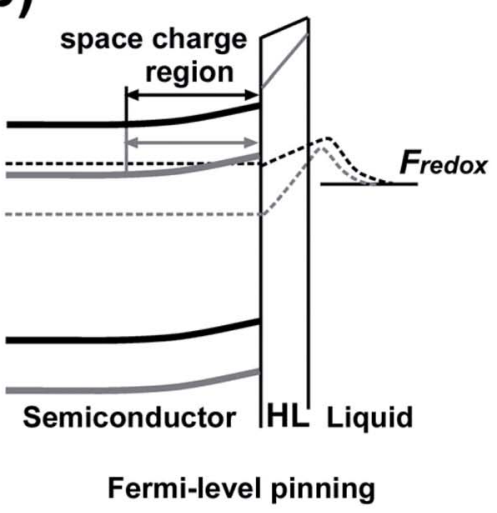

(c)

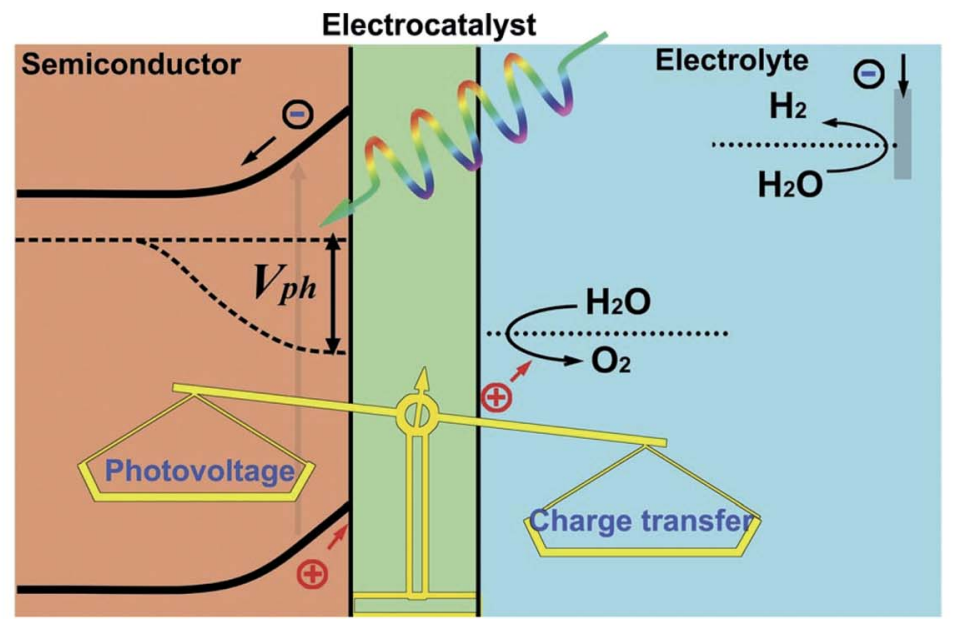

Fig. 4 Balance between photovoltage and surface charge transfer contribution, adapted from Journal of Catalysis, X. Yang et al., ref. 58, copyright (2013) with permission from Elsevier. (a) A typical J-V curve of a hematite photoanode without catalyst (black curve) and with a thin surface layer of $\mathrm{MnO}_{x}$ electrocatalyst (red curve) under water oxidation condition, with an inset of the band structure under illumination, where $V_{\mathrm{on}}, V_{\mathrm{ph}}, \eta, E\left(\mathrm{~A} / \mathrm{A}^{-}\right)$are the onset potential, photovoltage, overpotential and the redox pair potential, respectively; (b) band structure under Fermilevel pinning, where the applied bias is dropped across the Helmholtz layer instead of the semiconductor, unless the bias is high enough for the charge-carrier to transport to the surface through tunneling (the black and gray lines showed no potential drop in semiconductor under different applied bias); (c) schematic of the interfacial energetics with a catalytic passivation layer present, demonstrating the dual influence on both of the semiconductor side and electrolyte side. 
Thus the photovoltage generated in the semiconductor can be modulated from the interlayer side. The overall PEC water splitting performance would be determined by the interaction between the semiconductor's photovoltage and the charge transfer (or overpotential) as shown in eqn (2). An evaluation of the influence of surface layer on both sides is suggested to balance these contributions, especially when their contributions are conflicted to each other.

\section{Passivation layer stabilization against chemical corrosion}

Many semiconductor photoelectrodes, such as $\mathrm{Si}, \mathrm{ZnO}, \mathrm{Cu}_{2} \mathrm{O}$, and some binary or ternary metal sulfides are not stable in extreme $\mathrm{pH}$ electrolytes or at the high oxidative or reductive potentials required for water oxidation. ${ }^{72}$ In early work by Bard et al. ${ }^{73}$ and Gerischer et al. ${ }^{74}$ photocorrosion as a critical problem in a PEC cell was discussed: when the anodic (or cathodic) corrosion potential lies within the band gap, photocorrosion is competitive with water oxidation (or reduction). In these cases, the potential of the semiconductor corrosion reaction is typically less energetic and thus thermodynamically more favorable than the HER/OER reaction, leading to unstable photoelectrodes. ${ }^{75}$ Meanwhile, some metal oxides are kinetically stable under highly oxidizing conditions, while some nonoxide semiconductors or low valence metal oxides are kinetically stable to the reduction of photogenerated electrons.

One solution to corrosion is to coat the photoactive semiconductor with an inexpensive and easily synthesized corrosion-resistant layer. The layer must be, thin enough to allow interfacial charge transfer yet thick enough to provide chemical resistance to the electrolyte. Also, this introduced layer cannot destroy the semiconductor/liquid junction. In the case of photoanode protection in which the hole-conducting valenceband edges of chemically stable oxides are generally more positive than that of the photoactive material, research has shown that photogenerated holes cross the protective layer through a tunneling effect. Thus metal oxide protection layers are usually designed to be extremely thin, which also helps to minimize competing light absorption by the metal oxide layer.

Surface protection of unstable semiconductors started in the 1970 's, but most early results were based on a relatively thick layer of $\mathrm{TiO}_{2}$ on $\mathrm{Si}$, GaAs, GaP, or CdS single crystals. ${ }^{76}$ As a result, the semiconductor photoelectrodes while well protected, had poor photoelectrochemical performance due to the large interfacial charge-transfer resistance. With increasing research interest on the photoelectrodes in water splitting and the advancement of thin film fabrication techniques such as ALD, more promising results were achieved for unstable semiconductors with chemically-protective passivation layers (Table 2).

Silicon is one of the most promising narrow bandgap semiconductors $\left(E_{\mathrm{g}}=1.1 \mathrm{eV}\right)$, capable of absorbing a large portion of the solar spectrum $(<1100 \mathrm{~nm})$, with a theoretical maximum photocurrent of $\sim 43 \mathrm{~mA} \mathrm{~cm} \mathrm{~cm}^{-2}$ (before correcting for surface reflection). Si has been extensively studied as the most widely used semiconductor material, showing excellent light absorption properties. Further, silicon's small band gap makes it a promising material for use in dual or tandem junction semiconductor water splitting cells. However, bare $\mathrm{Si}$ photoelectrodes display poor stability in aqueous electrolyte for water oxidation, due to corrosion reactions, ${ }^{\mathbf{8 3}, 84}$ in which a surface $\mathrm{SiO}_{2}$ layer forms that inhibits charge transfer and decreases the photovoltage due to the formation of surface recombination sites. Previous studies have attempted passivation of Si with noble metals or noble metal silicides. ${ }^{\mathbf{8 5 , 8 6}}$ The potential of the

Table 2 Comparison of the stability of photoelectrodes protected with corrosion-resistant passivation layers

\begin{tabular}{|c|c|c|c|c|c|c|}
\hline \multirow[b]{2}{*}{ Working electrode } & \multicolumn{2}{|c|}{ Passivation layer } & \multirow[b]{2}{*}{ Electrolyte } & \multirow[b]{2}{*}{ Original stability } & \multirow{2}{*}{$\begin{array}{l}\text { Stability after } \\
\text { protection }\end{array}$} & \multirow[b]{2}{*}{ Ref. } \\
\hline & Materials & Thickness (nm) & & & & \\
\hline$n-S i$ & $\mathrm{TiO}_{2}$ & 2 & $1 \mathrm{M} \mathrm{H}_{2} \mathrm{SO}_{4}$ & A few minutes & $8 \mathrm{~h}$ & 31 \\
\hline $\mathrm{n}-\mathrm{Si}$ & $\mathrm{TiO}_{2}$ & 2 & $1 \mathrm{M} \mathrm{Na}_{2} \mathrm{HPO}_{4} / \mathrm{NaH}_{2} \mathrm{PO}_{4}(\mathrm{pH}=7)$ & $<3 \mathrm{~h}$ & $18 \mathrm{~h}$ & 31 \\
\hline$n-\mathrm{Si}$ & $\mathrm{TiO}_{2}$ & 2 & $1 \mathrm{M} \mathrm{NaOH}$ & $<0.5 \mathrm{~h}$ & $8 \mathrm{~h}$ & 31 \\
\hline$n-S i$ & Graphene & Mono layer & $\begin{array}{l}50 \mathrm{mM} \mathrm{K}_{3}\left[\mathrm{Fe}(\mathrm{CN})_{6}\right] / 350 \mathrm{mM} \\
\mathrm{K}_{4}\left[\mathrm{Fe}(\mathrm{CN})_{6}\right]\end{array}$ & $100 \mathrm{~s}$ & $1000 \mathrm{~s}$ & 49 \\
\hline $\mathrm{n}-\mathrm{ZnO}$ & $\mathrm{TiO}_{2}$ & $0.5-0.7$ & $1.1 \mathrm{M} \mathrm{KOH}(\mathrm{pH}=13)$ & - & $>3 \mathrm{~h}$ & 43 \\
\hline $\mathrm{n}-\mathrm{ZnO} / \mathrm{p}-\mathrm{Si}$ & $\mathrm{TiO}_{2}$ & 20 & $0.25 \mathrm{M} \mathrm{Na}_{2} \mathrm{SO}_{4}(\mathrm{pH}=7.25)$ & A few minutes & $24 \mathrm{~h}$ & 77 and 78 \\
\hline $\mathrm{p}-\mathrm{Si}$ & $\mathrm{TiO}_{2}$ & 100 & $1 \mathrm{M} \mathrm{HClO}_{4}$ & - & $72 \mathrm{~h}$ & 79 \\
\hline$(p-i-n) a-S i$ & $\mathrm{TiO}_{2}$ & 80 & $\begin{array}{l}0.5 \mathrm{M} \text { potassium hydrogen } \\
\text { phthalate }(\mathrm{pH}=4)\end{array}$ & $12 \mathrm{~h}(10 \%)^{a}$ & $12 \mathrm{~h}(95 \%)^{a}$ & 80 \\
\hline $\mathrm{p}-\mathrm{Cu}_{2} \mathrm{O}$ & $\mathrm{TiO}_{2}$ & 11 & $\begin{array}{l}1 \mathrm{M} \mathrm{Na}_{2} \mathrm{SO}_{4}-0.1 \mathrm{M} \mathrm{K}_{2} \mathrm{HPO}_{4} \\
(\mathrm{pH}=4.9)\end{array}$ & $<5 \min$ & $1 \mathrm{~h}$ & 81 \\
\hline $\mathrm{p}-\mathrm{Cu}_{2} \mathrm{O}$ & Carbon layer & 20 & $1 \mathrm{M} \mathrm{Na}_{2} \mathrm{SO}_{4}$ & $20 \min (12.6 \%)^{a}$ & $20 \min (87 \%)^{a}$ & 82 \\
\hline $\mathrm{p}-\mathrm{Cu}_{2} \mathrm{ZnSnS}_{4}$ & $\mathrm{TiO}_{2}$ & A few & $\begin{array}{l}0.5 \mathrm{M} \mathrm{KH}_{2} \mathrm{PO}_{4}-\mathrm{K}_{2} \mathrm{HPO}_{4} \\
(\mathrm{pH}=7) ; 0.1 \mathrm{M} \mathrm{Na}_{2} \mathrm{SO}_{4} \\
\mathrm{NaOH}(\mathrm{pH}=9)\end{array}$ & Within seconds & $15 \min$ & 44 \\
\hline $\mathrm{p}-\mathrm{InP}$ & $\mathrm{TiO}_{2}$ & $2-5$ & $1 \mathrm{M} \mathrm{HClO}_{4}(\mathrm{pH}=0.51)$ & 4 hours $67 \%$ & 4 hours (no decay) ${ }^{a}$ & 45 \\
\hline
\end{tabular}

${ }^{a}$ Authors compared the current density retention, and the protected electrodes showed much less current decay. 
top of the valence band of $\mathrm{n}-\mathrm{Si}$ is more negative than the thermodynamic water oxidation potential. However, a photoelectrochemical water oxidation reaction will occur with a sufficient applied bias (Fig. 5c). Recently, Chen et al. used ALD to coat a $2 \mathrm{~nm} \mathrm{TiO}_{2}$ thin layer on Si substrates, resulting in photoelectrodes which showed significantly improved corrosion resistance in neutral, strongly acidic, and strongly basic electrolytes (Fig. 5). ${ }^{31}$ The bare n-Si photoanodes quickly failed during anodic PEC measurements, while the $\mathrm{TiO}_{2}$ protected electrodes sustained at least 8 hours under light illumination condition. The measured photovoltages were 0.51-0.57 V, which are close to the open circuit potential (upwards of 700 $\mathrm{mV}$ ) for state-of-the-art silicon solar cells. ${ }^{87}$ Similar photoelectrochemical stability improvement using a graphene monolayer could be observed by Nielander et al., in an aqueous electrolyte of $\mathrm{Fe}(\mathrm{CN})_{6}{ }^{3-/ 4-} .^{49}$

Seger et al. has used a $100 \mathrm{~nm} \mathrm{TiO}_{2}$ layer protection onto an $\mathrm{n}^{+} \mathrm{p}$ Si photocathode by sputter deposition method. ${ }^{79}$ After annealing, the protected photocathode had a stable HER photocurrent for $72 \mathrm{~h}$ in $1 \mathrm{M} \mathrm{HClO}_{4}$ electrolyte. Although $\mathrm{TiO}_{2}$ is a n-type semiconductor, a metallic conductor behavior was found due to the alignment of the Si conduction band with the $\mathrm{TiO}_{2}$ conduction band and the hydrogen evolution potential. This method is also applied by Lin et al. to protect an amorphous $\mathrm{Si}$ in $\mathrm{ZnO} / \mathrm{p}-\mathrm{i}-\mathrm{n}$ a-Si photoelectrode using a $80 \mathrm{~nm} \mathrm{TiO}_{2}$ layer. ${ }^{80}$ The protected electrodes retained $95 \%$ of their initial photocurrent during $12 \mathrm{~h}$ hydrogen evolution in $0.5 \mathrm{M}$ potassium hydrogen phthalate solution compared with the $10 \%$ retention of the bare electrode. The a-Si photoelectrode also exhibit impressive photocurrent of $\sim 6.1 \mathrm{~mA} \mathrm{~cm}^{-2}$ at a positive potential of $0.8 \mathrm{~V}$.

Corrosion-resistant protection layers have also been applied with some success to stabilize materials as well. $\mathrm{ZnO}$ nanowire photoanodes, for instance, were chemically stabilized by the conformal growth of a $1 \mathrm{~nm} \mathrm{TiO}_{2}$ ultrathin shell through ALD, which showed a relatively high photocurrent density of $0.7 \mathrm{~mA}$ $\mathrm{cm}^{-2}$ in an alkaline solution $(0.1 \mathrm{M} \mathrm{KOH}) .{ }^{43}$ After $1 \mathrm{~h}$ under illumination, the onset potential of the electrode barely shifted. $\mathrm{TiO}_{2}$-protected $\mathrm{ZnO}$ photoelectrodes were observed to be stable as long as $3 \mathrm{~h}$, whereas the unprotected $\mathrm{ZnO}$ photocurrent decayed away within minutes.

For photoanodes, metal oxide surface layers often result in valence band edge alignment that is unfavorable for direct hole conduction. Thus charge transfer across the protection layer occurs primarily by tunneling. This requires ultrathin layers $(<2$ $\mathrm{nm}$ ) to be applied..$^{88}$ However, the fabrication of high quality, pinhole-free, ultrathin films on a large area or on a highly porous substrate is extremely challenging. Cracks or pinholes in the protecting layer are weak points where corrosion can undercut the barrier, decreasing the long-term stability under photoelectrochemical water-splitting. Thicker barrier layers, when feasible, reduce the likelihood of pinholes and provide (a)

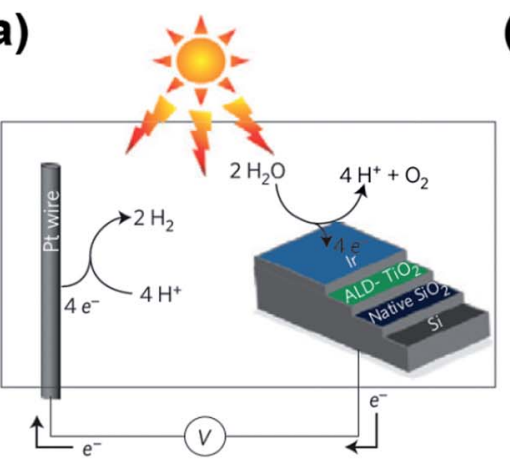

(b)

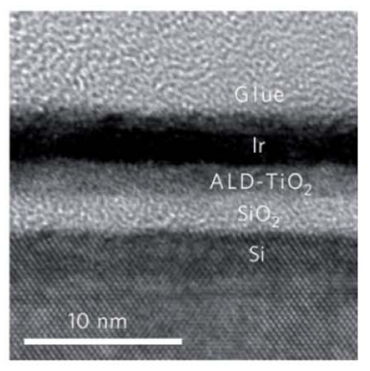

(e)

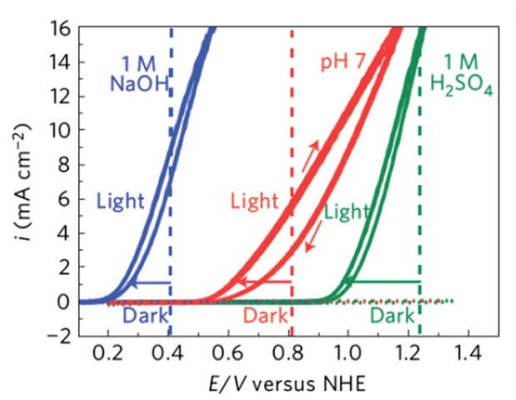

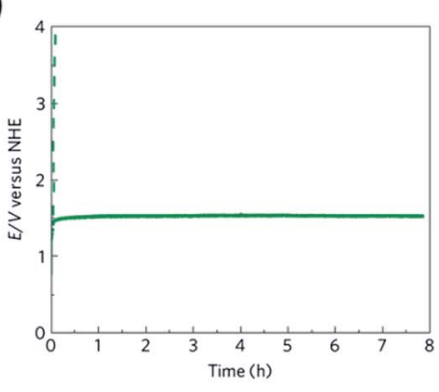

(c)

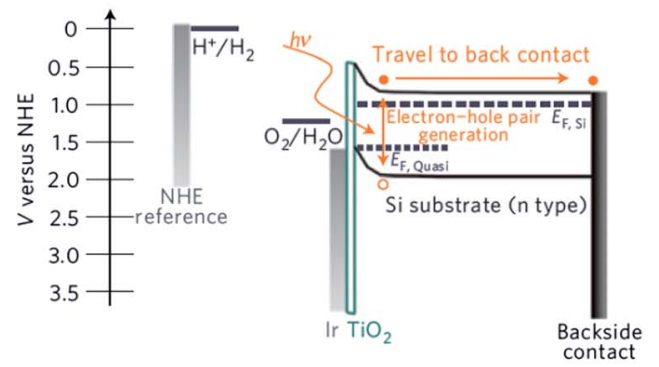

(f)

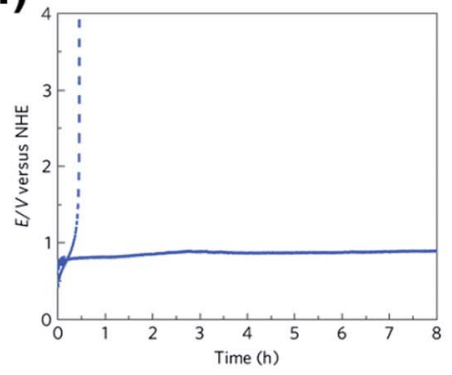

Fig. $5 \mathrm{Ir} / \mathrm{TiO}_{2} / \mathrm{Si}$ nanocomposite water oxidation anode, adapted from ref. 31 by permission from Macmillan Publishers Ltd: Nature, copyright 2011. (a) Schematic and (b) TEM image of the nanocomposite anode. (c) Approximate energy band diagram of nanocomposite anode at $1 \mathrm{~V}$ versus NHE under illumination in $\mathrm{pH}=0$ solution. (d) Water electrolysis using $\mathrm{n}$-Si substrates in the dark for acidic (green dots), neutral (red dots), and basic (blue dots) solutions and 1 sun solar simulated light for acidic (green solid line), neutral (red line), and basic (blue line) solutions. (e) Anode stability under illumination during water splitting in $1 \mathrm{M}$ acid with (green solid line) and without (green dashed line) the $\mathrm{TiO}_{2}$ protection

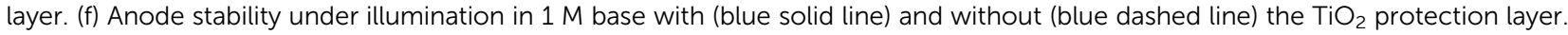


better stability. When $\mathrm{ZnO}$ nanowires were grown as branches on $\mathrm{Si}$ nanowire trunks with a $20 \mathrm{~nm} \mathrm{TiO}_{2}$ protective layer, the heterostructured photoelectrode showed an energy conversion efficiency of $2 \%{ }^{77}$ and stable photoelectrochemical performance over $24 \mathrm{~h}$ under illumination. ${ }^{78}$

Thicker $\mathrm{TiO}_{2}$ layers $(10-20 \mathrm{~nm})$ have also been used to protect highly porous substrates and highly reactive $\mathrm{Cu}_{2} \mathrm{O}$ (or $\mathrm{ZnO})$ substrates. The main limiting factor for the use of $\mathrm{p}$ $\mathrm{Cu}_{2} \mathrm{O}$ as a photocathode for water reduction is its poor stability in aqueous solution, because the potentials for the reduction and oxidation of monovalent copper oxide lie between the valence band and conduction band. ${ }^{75}$ Paracchino et al. deposited conformal Al-doped $\mathrm{ZnO}$ and $\mathrm{TiO}_{2}(11 \mathrm{~nm})$ by ALD onto a $1.3 \mu \mathrm{m}$ thick $\mathrm{p}-\mathrm{Cu}_{2} \mathrm{O}$ film, which showed an optimized photocurrent $\left(\sim 7.6 \mathrm{~mA} \mathrm{~cm}^{-2}\right)$ at $0 \mathrm{~V}$ vs. RHE. ${ }^{81}$ The $\mathrm{p}-\mathrm{Cu}_{2} \mathrm{O}$ photocathode was stable during the measurement for $1 \mathrm{~h}$ with a Faradaic efficiency for hydrogen evolution close to $100 \%$. Besides the more common $\mathrm{TiO}_{2}$ protective layer, a carbon layer was also demonstrated to protect p-type $\mathrm{Cu}_{2} \mathrm{O}$ nanowires. Zhang et al. coated $\mathrm{Cu}_{2} \mathrm{O}$ nanowire arrays with a $20 \mathrm{~nm}$ carbon coating using a glucose precursor, then tested the arrays as photocathodes. They yielded a photocurrent density of 3.95 $\mathrm{mA} \mathrm{cm} \mathrm{cm}^{-2}$ and an efficiency of $0.56 \%$. Over $20 \mathrm{~min}$ the photocurrent maintained $80.7 \%$ of its initial value, while the unprotected sample only retained $12.6 \%{ }^{82}$ In another photocathode stabilization study, a composite protective layer with $\mathrm{TiO}_{2}$, Al-doped $\mathrm{ZnO}$, and CdS sections was applied to a p$\mathrm{Cu}_{2} \mathrm{ZnSnS}_{4}$ thin film semiconductor, with a Pt HER catalyst decorated on the top $\mathrm{TiO}_{2}$ surface. These earth-abundant photocathodes showed $>1 \mathrm{~mA} \mathrm{~cm} \mathrm{~cm}^{-2}$ photocurrent in an aqueous near-neutral $\mathrm{pH}$ electrolyte with a significant stability improvement over unprotected electrodes. ${ }^{\mathbf{4}}$

Since the IV, III-V and II-VI sulfide groups of semiconductors are chemically and/or electrochemically unstable in aqueous electrolyte for water-splitting, these materials are prime candidates for improvement by metal oxide protective layer stabilization. ${ }^{\mathbf{8 4 , 8 9}}$ Faster photocurrent decay is expected on an unstable bare semiconductor compared to a protected one, because the corrosion of the photoactive semiconductor gradually reduces its effectiveness as a light absorber. In addition to optical thinning, corrosion can lead to a high surface defect density, inducing increased surface recombination. Under these conditions, the semiconductor does not survive long. In other semiconductors, such as $\mathrm{Si}$, the material instability results in the formation of an insulating layer (i.e., $\mathrm{SiO}_{2}$ ) that inhibits charge transfer and shuts down the semiconductor photoactivity as the layer becomes thicker. By depositing a stable, conformal, surface layer, the photoactive semiconductor is shielded from the electrolyte, and cannot drive the semiconductor corrosion reaction. However, photogenerated minority-carriers must transfer through the protective layer to the surface to react with water molecules. The application of an inert surface coating such as $\mathrm{TiO}_{2}$ may improve the photoelectrode stability, but will not provide a catalytic surface for water oxidation or reduction. Thus an additional co-catalyst may be needed to lower the overpotential to produce an efficient water-splitting photoelectrode.
Based on the work by Wang et al. ${ }^{75}$ a material is thermodynamically unstable and photocorrosion occurs when the potential for the material oxidation, $\phi^{\text {ox }}$, is more negative than the oxygen evolution potential, $E\left(\mathrm{O}_{2} / \mathrm{H}_{2} \mathrm{O}\right)$, shown in (Fig. 6a). Alternatively, when $\phi^{\text {ox }}$ is positive of the VBM, the material is thermodynamically stable. ${ }^{75}$ When $E\left(\mathrm{O}_{2} / \mathrm{H}_{2} \mathrm{O}\right)<\phi^{\mathrm{ox}}<E_{\mathrm{VBM}}$, the material stability depends on the relative holes consuming rates for water oxidation $v s$. surface oxidation of the electrode. Similar arguments can be made for a photocathode (Fig. 6b). This conclusion is true, if the overpotential of water splitting is negligible. It is also applicable for the stability of passivation layer. And when the $\phi^{\text {ox }^{\prime}}$ of the surface layer is positive than the VBM of the photoabsorber, it can work as a protection layer for the photoabsorber from corrosion (Fig. 6c).

$\mathrm{TiO}_{2}$ layer has been used as a passivation layer to protect those unstable photoelectrodes (Table 2). If working as a photoanode, $\mathrm{TiO}_{2}$ is not thermodynamically stable but kinetically stable, since $E\left(\mathrm{O}_{2} / \mathrm{H}_{2} \mathrm{O}\right)<\phi^{\mathrm{ox}}\left(\mathrm{TiO}_{2}\right)<E_{\mathrm{VBM}}\left(\mathrm{TiO}_{2}\right) .{ }^{74,90}$ However, when used as a surface passivation layer, $\phi^{\text {ox }}\left(\mathrm{TiO}_{2}\right)$ will be more positive than the VBM of the underlying photoabsorber material. The holes generated by the photoabsorber do not have sufficient energy to oxidize $\mathrm{TiO}_{2}$, but enough for the water oxidation reaction (Fig. 6c). In this way, an unstable photoanode can be protected from anodic corrosion by using a conformal $\mathrm{TiO}_{2}$ coating. For the case of a photocathode absorber, the
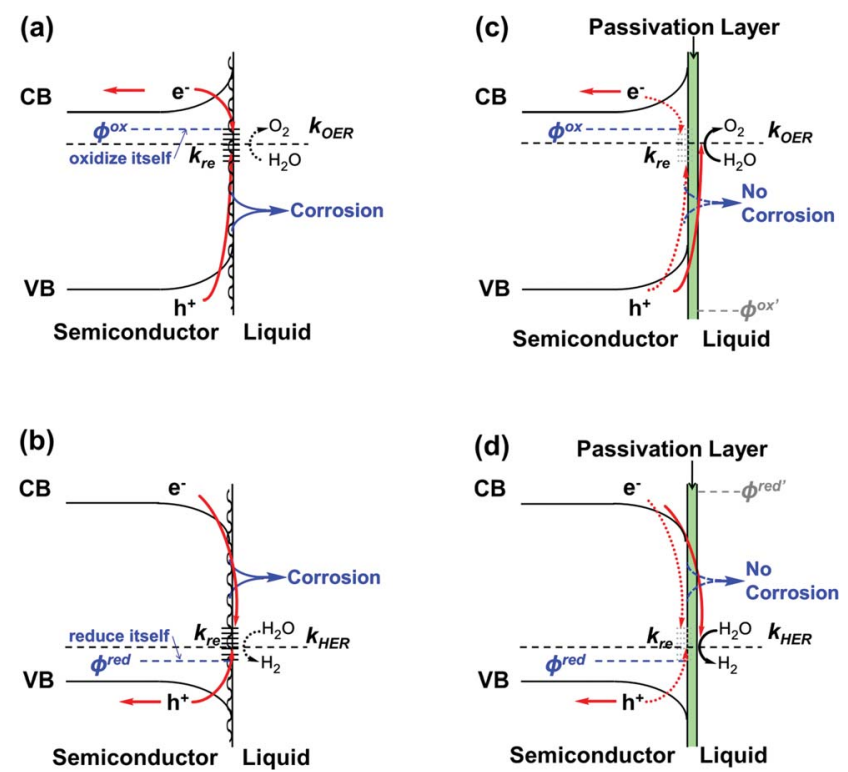

Fig. 6 Comparison of a semiconductor photoelectrode with/without a stabilizing passivation layer. A schematic illustration of the band structure of an (a) n-type and (b) p-type semiconductor photoelectrode experiencing corrosion when contacting an aqueous electrolyte, (c) n-type and (d) p-type semiconductor protected from corrosion with passivation layer. $\phi^{\text {ox }}$ stands for the corrosion potential of the n-type semiconductor, which should be more positive than the OER reaction energy level; and $\phi^{\text {red }}$ stands for the corrosion potential of the p-type semiconductor, which is more negative than the HER. Corrosion may reduce the light absorption and/or generate more surface defect states, resulting in a more positive onset potential and a reduced photocurrent. 
cathodic corrosion potential of $\mathrm{TiO}_{2}\left(\phi^{\mathrm{red}^{\prime}}\right)$ is more negative than the CBM of both the photoabsorber and $\mathrm{TiO}_{2}$, making the $\mathrm{TiO}_{2}$ thermodynamically stable (Fig. 6d) and protection the underlying electrode. Thus a conformal ALD layer of $\mathrm{TiO}_{2}$ has often been used as a surface passivation layer. For similar reasons, other metal oxides, such as $\mathrm{CuWO}_{4}, \mathrm{Co}_{3} \mathrm{O}_{4}, \mathrm{SnO}_{2}, \mathrm{WO}_{3}$, $\mathrm{Ta}_{2} \mathrm{O}_{5}$ etc., can server as a passivation layer for photoanodes, while $\mathrm{BaTiO}_{3}$ and $\mathrm{Ta}_{2} \mathrm{O}_{5}$ could be used for photocathodes.

\section{Passivation layers combining multiple benefits}

The effects of surface recombination passivation, catalytic improvement in interfacial charge transfer kinetics, and chemical stabilization are not necessarily independent. Welldesigned solar water-splitting devices have combined these properties to enhance overall performance. Numerous literature examples have used catalyst/passivation layers to gain multiple benefits to improve a photoactive material. For example, OER or HER catalysts are widely suggested as passivation layer on photoelectrodes, because the catalytic properties would reduce the overpotential of water splitting reactions on the interface of the photoelectrode/electrolyte, on the other hand, the charge recombination and surface corrosion would be suppressed due to the faster reaction kinetics and reduced minority carrier density. Liu et al. 's work introduced a BrudvigCrabtree catalyst (Mn-oxo OER catalyst) thin layer onto the surface of $\mathrm{WO}_{3}$ photoelectrode. The $\mathrm{WO}_{3}$ has poor stability at $\mathrm{pH}>4$. This design not only improved the reaction kinetics of the $\mathrm{O}_{2}$ evolution reaction, but also protected the $\mathrm{WO}_{3}$ photoelectrode from electrolyte corrosion in a neutral $\mathrm{pH}$ environment for hours. ${ }^{\mathbf{5 0 5 1}}$ Strandwitz et al. reported a $10 \mathrm{~nm} \mathbf{M n O}_{x}$ layer coated onto n-Si photoanodes by ALD that displayed opencircuit voltages of up to $550 \mathrm{mV} \cdot{ }^{91}$ The protected n-Si anodes showed stable oxygen evolution with current densities of $\sim 25$ $\mathrm{mA} \mathrm{cm}{ }^{-2}$ for $30 \mathrm{~min}$ in $1.0 \mathrm{M} \mathrm{KOH}$ solution. Although bare $\mathrm{Si}$ photoanodes displayed negligible photoactivity, an ALD $\mathrm{MnO}_{x}$ layer not only promoted the OER catalysis, but also chemically stabilized the Si electrode in alkaline solution. Similarly, Sun et al. also successfully improved Si photoanode PEC performance by sputtering a $\mathrm{NiRuO}_{x}$ catalyst layer on the surface, which simultaneously functioned as a hole conducting layer for efficient charge transport, and an electrocatalyst to reduce the kinetic overpotential. ${ }^{92}$ A $37.4 \mathrm{~nm} \mathrm{NiO}{ }_{x}$ OER electrocatalyst layer was also employed on a Si photoanode by a sol-gel method, showing a cathodic shift of $V_{\text {on,A }}$ to $1.18 \mathrm{~V} v$ s. RHE and a $1.34 \%$ of overall conversion efficiency. ${ }^{93}$ For longer-term stability PEC devices with a cost-effective electrocatalyst, Kenny et al., recently used a $2 \mathrm{~nm}$ Ni film on n-type silicon with a native silicon oxide layer as a high performance metal-insulator-semiconductor photoanode for water oxidation in aqueous $\mathrm{KOH}$ solution

\section{(a)}

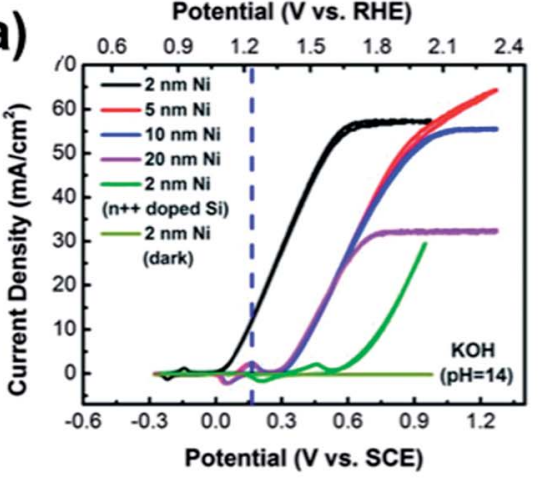

(b)

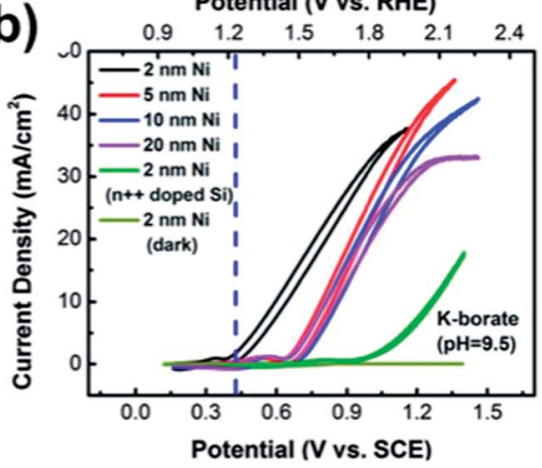

(c)

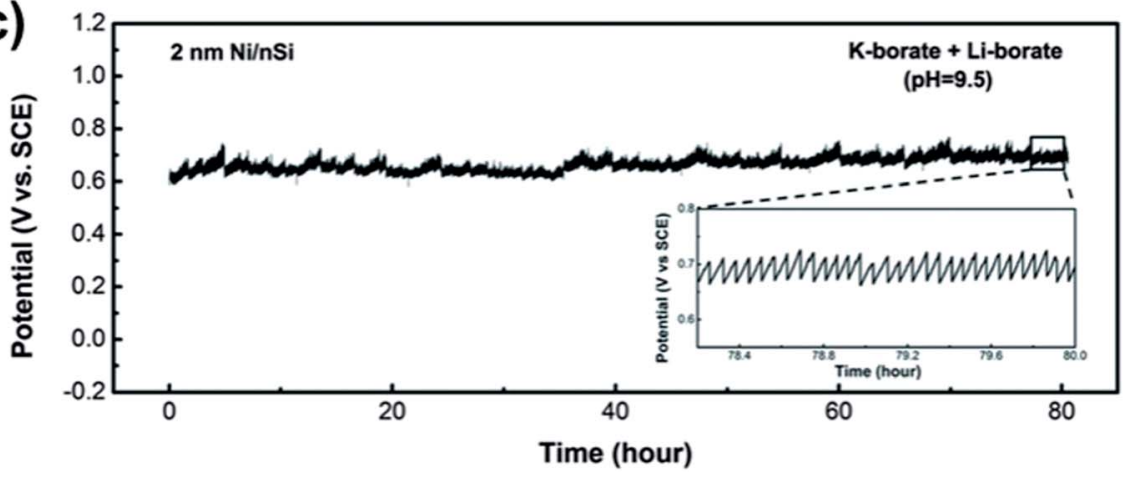

Fig. 7 High-performance Ni/n-Si photoanode with ultrahigh stability, adapted from ref. 48 reprinted with permission from AAAS. (a) Cyclic voltammograms of 2-, 5-, 10-, and $20 \mathrm{~nm} \mathrm{Ni}$-coated $\mathrm{n}$-Si anodes in $1 \mathrm{M} \mathrm{KOH}$ under illumination with a xenon, $2 \mathrm{~nm} \mathrm{Ni-coated} \mathrm{n}$-Si anode in the dark, and $2 \mathrm{~nm} \mathrm{Ni}$ on metallic, heavily doped $\mathrm{n}^{++} \mathrm{Si}$ in the dark. (b) Cyclic voltammograms of 2-, 5-, $10-$, and $20 \mathrm{~nm} \mathrm{Ni-coated} \mathrm{n-Si} \mathrm{anodes} \mathrm{in} 1 \mathrm{M}$ $\mathrm{K}$-borate electrolyte under illumination, $2 \mathrm{~nm} \mathrm{Ni}$-coated $\mathrm{n}$-Si anode in the dark, and $2 \mathrm{~nm} \mathrm{Ni}$ on metallic, heavily doped $\mathrm{n}^{++} \mathrm{Si}$ in the dark. (c) Potential versus time data, under constant current density of $10 \mathrm{~mA} \mathrm{~cm}^{-2}$, of a $2 \mathrm{~nm} \mathrm{Ni} / \mathrm{n}$-Si anode in $0.65 \mathrm{M} \mathrm{K}$-borate and $0.35 \mathrm{M} \mathrm{Li}$-borate (pH $=$ 9.5) for 80 hours (>3 days) under constant illumination. 
$(\mathrm{pH}=14)$ and potassium borate solution $(\mathrm{pH}=9.5){ }^{48}$ The Ni film significantly improved the photostability of n-Si to $\sim 80 \mathrm{~h}$ in mixed lithium borate-potassium borate electrolyte (Fig. 7).

Discontinuous catalytic passivation layers can promote water-splitting relative to the photocorrosion reaction while having less parasitic photon absorption than thick conformal layers that block access of the electrolyte to the semiconductor surface. It is reported that $\mathrm{IrO}_{2}$ or $\mathrm{CoO}_{x}$ catalyst nanoparticles (a few $\mathrm{nm}$ in diameter) dramatically increased the stability (from tens of seconds to $\sim 1 \mathrm{~h}$ ) of TaON photoanodes in $0.1 \mathrm{M}$ aqueous $\mathrm{Na}_{2} \mathrm{SO}_{4}$ or sodium phosphate buffer solution. The catalyst acted as a hole scavenger and reduced the self-oxidation of the electrode surface. ${ }^{63,94}$ Likewise, Liao et al. used $\mathrm{Co}_{3} \mathrm{O}_{4}$ nanoparticles as an OER catalyst to improve the photostability of $\mathrm{Ta}_{3} \mathrm{~N}_{5}$ photoanodes. ${ }^{95}$ Although the bare Ta-based photoanodes suffered serious photocorrosion due to hole-induced self-oxidation at the positive potentials of water oxidation, the introduction of an OER catalyst protected the semiconductor by improving the transfer of photogenerated holes to the catalytic sites and thus reducing the hole concentration at the surface. After catalyst deposition, approximately $75 \%$ of the initial photocurrent remained after $2 \mathrm{~h}$ illumination. In another example, $\mathrm{p}-\mathrm{Cu}_{2} \mathrm{O}$ nanowire-based photocathodes were protected by a $10 \mathrm{~nm} \mathrm{NiO} x$ catalyst ( $\mathrm{NiO}$ and $\mathrm{Ni}(\mathrm{OH})_{2}$ mixture) layer, resulting in enhanced photocurrents due to improved charge transfer to solution. The $\mathrm{Cu}_{2} \mathrm{O}$ photocathodes retained $72.3 \%$ of their initial photocurrent density with the $\mathrm{NiO}_{x}$ modification after 20 min under illumination at $0.1 \mathrm{~V}$ (vs. NHE) in aqueous electrolyte. ${ }^{96}$

CdS has been studied as a thin passivation layer that can improve the photoelectrochemical properties of $\mathrm{CuGaSe}_{2}$. In this system, the CdS layer formed a $\mathrm{p}-\mathrm{n}$ heterojunction with the $\mathrm{CuGaSe}_{2}$, and improved photoelectrode stability in $0.1 \mathrm{M}$ $\mathrm{Na}_{2} \mathrm{SO}_{4}(\mathrm{pH}=9)$. The system evolved hydrogen continuously for more than 10 days. ${ }^{97}$ A heterojunction CdSe/CdS photoelectrode was reported that used $\mathrm{IrO}_{x}$ nanoparticles as an OER catalyst layer. ${ }^{98}$ The $\mathrm{IrO}_{x}$ reduced recombination by promoting the interfacial transfer of photogenerated holes across the surface of the CdSe/CdS, which improved the photoelectrode stability and resulted in $>95 \%$ of the photocurrent retained after $3 \mathrm{~h}$ under operation in aqueous solution at $\mathrm{pH}$ 12.5.

Fully understanding and deconvoluting the multiple effects of a single surface layer on a semiconductor is complex, ${ }^{99}$ as its contributions can include surface state passivation, enhanced interfacial charge-transfer kinetics, suppression of corrosion reactions, buried junction effects and surface band position shifts relative to the solution. Layers can also enhance photoelectrode stability, either by physically isolating the semiconductor from the solution, or by promoting water-splitting relative to photocorrosion. Some demonstrated techniques for evaluating the interplay between these mechanisms include transient absorption spectroscopy, ${ }^{\mathbf{1 0 0}}$ impedance spectroscopy and transient photocurrent spectroscopy, ${ }^{26}$ and photovoltage measurements. ${ }^{58,101}$ In a "well" designed system (Fig. 8a and b), there will be passivated surface trap states, a fast interfacial charge-transfer rate for water splitting, and a very slow rate of photocorrosion. Furthermore, the light absorption of the surface passivation layers must be negligible. A good
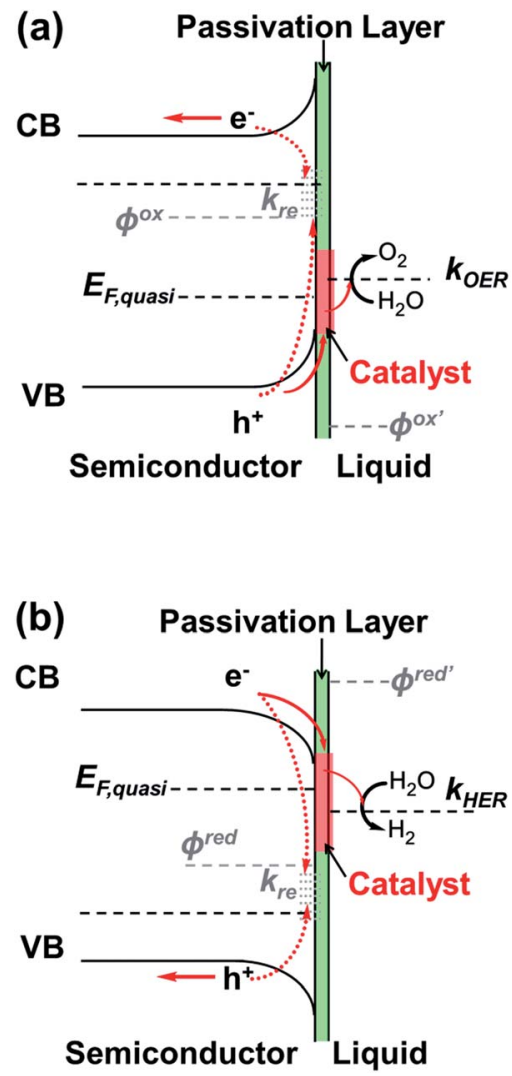

Fig. 8 Schematic illustration of the band structure for a surface passivation layer on (a) an n-type semiconductor (b) p-type semiconductor for photoelectrochemical water splitting. The photogenerated holes near the surface are in competition between trap site induced recombination with majority-carrier electrons and chargetransfer to the surface layer. By passivating the surface, the surface recombination rate $\left(k_{\mathrm{re}}\right)$ and electrode corrosion are suppressed and the interfacial charge-transfer rate for water oxidation $\left(k_{\mathrm{OER}}\right)$ is improved.

passivation layer should meet at least one of these requirements without detrimentally affecting the other processes. Even with the prospect of multiple passivation benefits, it is difficult for a single layer material to provide all the benefits for efficient water-splitting applications. While $\mathrm{TiO}_{2}$ layers have been widely applied with significant success at surface state passivation and chemical stabilization, most photoelectrode materials still require an additional catalyst to reduce the kinetic overpotential. ${ }^{31}$ Moreover, in some systems, it can be difficult to achieve a thin, conformal layer of a desired electrocatalyst on the substrate, ${ }^{27,59,94}$ even by ALD. ${ }^{102}$ To achieve optimal results in these cases, composite layers containing both inert passivating and catalytic material may be needed. Future research is needed to improve both the fabrication and the characterization of complex, functional interfacial layers.

\section{Conclusion and perspective}

Solar water-splitting is a promising approach for sustainable clean fuels, with high theoretical efficiencies for converting 
solar energy to a dense, portable chemical energy form. Numerous earth-abundant materials $\left(\mathrm{Si}, \mathrm{Fe}_{2} \mathrm{O}_{3}, \mathrm{WO}_{3}, \mathrm{BiVO}_{4}\right.$, $\mathrm{Cu}_{2} \mathrm{O}$, etc.) have been proposed as photoactive components for photoelectrochemical devices, but they face a myriad of challenges to be implemented in an efficient system. Robust chemical stability, high light absorption, good charge-carrier collection, low reaction overpotentials, and a large photovoltage are all needed for an ideal photoelectrode. In particular, interfacial charge transfer is a key issue when introducing a semiconductor into liquid electrolyte. Surface passivation layers can improve the photoelectrode and enhance charge transfer efficiency by suppressing the surface state density, providing an alternative lower energy route for charge transfer through catalytically active sites, protecting photoelectrodes from chemical corrosion. Thus surface layer treatments have the potential to significantly improve overall PEC water splitting performance.

Although significant advantages are possible through the use of a surface passivation layer, new issues may arise. The surface layer(s) creates new interfaces that must be considered. While a surface layer can improve one property, it may worsen another property simultaneously. However, the engineering of multiple component passivation layers can provide a solution for many material problems encountered in PEC water splitting.

To date, the achieved efficiencies of water-splitting by semiconductor-based photoelectrochemical cells are still lower than that needed in a practical device, due either to a lack of suitable candidate materials, or to stability limitations under harsh reaction conditions. Fortunately, the performance improvements enabled by surface passivation layers provide the possibility for the further optimization of these PEC systems.

\section{Acknowledgements}

The authors would like to acknowledge Dr. Bruce S. Brunschwig from Molecular Materials Research Center in California Institution of Technology for his valuable comments and suggestions to improve the manuscript. This material is based upon work performed by the Joint Center for Artificial Photosynthesis, a DOE Energy Innovation Hub, and Xuchang University, as follows: Rui Liu and Joshua Spurgeon are supported through the Office of Science of the U.S. Department of Energy under Award no. DESC0004993; Zhi Zheng and Xiaogang Yang are supported by Henan Province office of education (14B150013), Innovation Scientists and Technicians Troop Construction Projects of Henan Province (Grant no. 144200510014) and National Natural Science Foundation of China under Grant no. 21273192.

\section{References}

1 A. Kudo and Y. Miseki, Chem. Soc. Rev., 2009, 38, 253-278.

2 IEA, Key World Energy Statistics, OECD Publishing, 2010.

3 A. Fujishima and K. Honda, Nature, 1972, 238, 37-38.

4 O. Khaselev and J. A. Turner, Science, 1998, 280, 425-427.

5 M. Gratzel, Chem. Lett., 2005, 34, 8-12.

6 N. S. Lewis and D. G. Nocera, Proc. Natl. Acad. Sci. U. S. A., 2006, 103, 15729-15735.
7 D. Ginley, M. A. Green and R. Collins, MRS Bull., 2008, 33, 355-364.

8 M. G. Walter, E. L. Warren, J. R. McKone, S. W. Boettcher, Q. X. Mi, E. A. Santori and N. S. Lewis, Chem. Rev., 2010, 110, 6446-6473.

9 X. Chen, S. Shen, L. Guo and S. S. Mao, Chem. Rev., 2010, 110, 6503-6570.

10 M. Gratzel, Nature, 2001, 414, 338-344.

11 S. Licht, B. Wang, S. Mukerji, T. Soga, M. Umeno and H. Tributsch, Int. J. Hydrogen Energy, 2001, 26, 653-659.

12 H. Dotan, O. Kfir, E. Sharlin, O. Blank, M. Gross, I. Dumchin, G. Ankonina and A. Rothschild, Nat. Mater., 2013, 12, 158-164.

13 M. S. Prévot and K. Sivula, J. Phys. Chem. C, 2013, 117, 17879-17893.

14 S. K. Mohapatra, S. E. John, S. Banerjee and M. Misra, Chem. Mater., 2009, 21, 3048-3055.

15 S. W. Boettcher, J. M. Spurgeon, M. C. Putnam, E. L. Warren, D. B. Turner-Evans, M. D. Kelzenberg, J. R. Maiolo, H. A. Atwater and N. S. Lewis, Science, 2010, 327, 185-187.

16 A. Mao, K. Shin, J. K. Kim, D. H. Wang, G. Y. Han and J. H. Park, ACS Appl. Mater. Interfaces, 2011, 3, 1852-1858.

17 Y. Lin, G. Yuan, R. Liu, S. Zhou, S. W. Sheehan and D. Wang, Chem. Phys. Lett., 2011, 507, 209-215.

18 M. D. Kelzenberg, D. B. Turner-Evans, M. C. Putnam, S. W. Boettcher, R. M. Briggs, J. Y. Baek, N. S. Lewis and H. A. Atwater, Energy Environ. Sci., 2011, 4, 866-871.

19 S. W. Boettcher, E. L. Warren, M. C. Putnam, E. A. Santori, D. Turner-Evans, M. D. Kelzenberg, M. G. Walter, J. R. McKone, B. S. Brunschwig, H. A. Atwater and N. S. Lewis, J. Am. Chem. Soc., 2011, 133, 1216-1219.

20 L. Li, Y. Yu, F. Meng, Y. Tan, R. J. Hamers and S. Jin, Nano Lett., 2012, 12, 724-731.

21 C. Liu, N. P. Dasgupta and P. Yang, Chem. Mater., 2013, 26, 415-422.

22 Y. J. Hwang, C. Hahn, B. Liu and P. Yang, ACS Nano, 2012, 6, 5060-5069.

23 Y. Lin, S. Zhou, S. W. Sheehan and D. Wang, J. Am. Chem. Soc., 2011, 133, 2398-2401.

24 Y. Lin, G. Yuan, S. W. Sheehan, S. Zhou and D. Wang, Energy Environ. Sci., 2011, 4, 4862-4869.

25 J. Shi and X. Wang, Energy Environ. Sci., 2012, 5, 7918-7922. 26 B. Klahr, S. Gimenez, F. Fabregat-Santiago, J. Bisquert and T. W. Hamann, J. Am. Chem. Soc., 2012, 134, 16693-16700.

27 P. Dai, J. Xie, M. T. Mayer, X. Yang, J. Zhan and D. Wang, Angew. Chem., Int. Ed., 2013, 52, 11119-11123.

28 B. Seger, A. B. Laursen, P. C. K. Vesborg, T. Pedersen, O. Hansen, S. Dahl and I. Chorkendorff, Angew. Chem., Int. Ed., 2012, 51, 9128-9131.

29 R. L. Grimm, M. J. Bierman, L. E. O'Leary, N. C. Strandwitz, B. S. Brunschwig and N. S. Lewis, J. Phys. Chem. C, 2012, 116, 23569-23576.

30 Y. Lin, Y. Xu, M. T. Mayer, Z. I. Simpson, G. McMahon, S. Zhou and D. Wang, J. Am. Chem. Soc., 2012, 134, 5508-5511.

31 Y. W. Chen, J. D. Prange, S. Dühnen, Y. Park, M. Gunji, C. E. D. Chidsey and P. C. McIntyre, Nat. Mater., 2011, 10, 539-544. 
32 F. Le Formal, N. Tetreault, M. Cornuz, T. Moehl, M. Gratzel and K. Sivula, Chem. Sci., 2011, 2, 737-743.

33 M. Barroso, A. J. Cowan, S. R. Pendlebury, M. Grätzel, D. R. Klug and J. R. Durrant, J. Am. Chem. Soc., 2011, 133, 14868-14871.

34 K. P. Pande, Y. S. Hsu, J. M. Borrego and S. K. Ghandhi, Appl. Phys. Lett., 1978, 33, 717-719.

35 B. Miller, A. Heller, S. Menezes and H. J. Lewerenz, Faraday Discuss. Chem. Soc., 1980, 70, 223-232.

$36 \mathrm{H}$. Yoneyama, Y. Murao and H. Tamura, J. Electroanal. Chem. Interfacial Electrochem., 1980, 108, 87-96.

37 F. Le Formal, S. R. Pendlebury, M. Cornuz, S. D. Tilley, M. Grätzel and J. R. Durrant, J. Am. Chem. Soc., 2014, 136, 2564-2574.

38 K. Sivula, J. Phys. Chem. Lett., 2013, 4, 1624-1633.

39 T. P. Brennan, J. T. Tanskanen, K. E. Roelofs, J. W. F. To, W. H. Nguyen, J. R. Bakke, I. K. Ding, B. E. Hardin, A. Sellinger, M. D. McGehee and S. F. Bent, J. Phys. Chem. C, 2013, 117, 24138-24149.

40 S. S. Pandey, S. Sakaguchi, Y. Yamaguchi and S. Hayase, Org. Electron., 2010, 11, 419-426.

41 S. C. Riha, B. M. Klahr, E. C. Tyo, S. Seifert, S. Vajda, M. J. Pellin, T. W. Hamann and A. B. F. Martinson, ACS Nano, 2013, 7, 2396-2405.

42 T. Hisatomi, F. Le Formal, M. Cornuz, J. Brillet, N. Tetreault, K. Sivula and M. Gratzel, Energy Environ. Sci., 2011, 4, 2512-2515.

43 M. Liu, C.-Y. Nam, C. T. Black, J. Kamcev and L. Zhang, J. Phys. Chem. C, 2013, 117, 13396-13402.

44 L. Rovelli, S. D. Tilley and K. Sivula, ACS Appl. Mater. Interfaces, 2013, 5, 8018-8024.

45 M. H. Lee, K. Takei, J. Zhang, R. Kapadia, M. Zheng, Y.-Z. Chen, J. Nah, T. S. Matthews, Y.-L. Chueh, J. W. Ager and A. Javey, Angew. Chem., Int. Ed., 2012, 51, 1076010764.

46 T. Wang, Z. Luo, C. Li and J. Gong, Chem. Soc. Rev., 2014, DOI: $10.1039 / \mathrm{c} 3 \mathrm{cs} 60370 \mathrm{a}$.

47 J. G. Li, S. Kim, S. Edington, J. Nedy, S. Cho, K. Lee, A. J. Heeger, M. C. Gupta and J. T. Yates, Sol. Energy Mater. Sol. Cells, 2011, 95, 1123-1130.

48 M. J. Kenney, M. Gong, Y. Li, J. Z. Wu, J. Feng, M. Lanza and H. Dai, Science, 2013, 342, 836-840.

49 A. C. Nielander, M. J. Bierman, N. Petrone, N. C. Strandwitz, S. Ardo, F. Yang, J. Hone and N. S. Lewis, J. Am. Chem. Soc., 2013, 135, 17246-17249.

50 R. Liu, Y. Lin, L.-Y. Chou, S. W. Sheehan, W. He, F. Zhang, H. J. M. Hou and D. Wang, Angew. Chem., Int. Ed., 2011, 50, 499-502.

51 L.-Y. Chou, R. Liu, W. He, N. Geh, Y. Lin, E. Y. F. Hou, D. Wang and H. J. M. Hou, Int. J. Hydrogen Energy, 2012, 37, 8889-8896.

52 Z. Li, W. Luo, M. Zhang, J. Feng and Z. Zou, Energy Environ. Sci., 2013, 6, 347-370.

53 A. K. Ghosh, C. Fishman and T. Feng, J. Appl. Phys., 1980, 51, 446-454.

54 I. Visoly-Fisher, S. R. Cohen, A. Ruzin and D. Cahen, Adv. Mater., 2004, 16, 879-883.
55 K. Peng, Y. Xu, Y. Wu, Y. Yan, S.-T. Lee and J. Zhu, Small, 2005, 1, 1062-1067.

56 K. Sivula, F. Le Formal and M. Grätzel, ChemSusChem, 2011, 4, 432-449.

57 P. C. Searson, P. V. Nagarkar and R. M. Laianision, Int. J. Hydrogen Energy, 1989, 14, 131-136.

58 X. Yang, C. Du, R. Liu, J. Xie and D. Wang, J. Catal., 2013, 304, 86-91.

59 S. D. Tilley, M. Cornuz, K. Sivula and M. Gratzel, Angew. Chem., Int. Ed., 2010, 49, 6405-6408.

60 L. Badia-Bou, E. Mas-Marza, P. Rodenas, E. M. Barea, F. Fabregat-Santiago, S. Gimenez, E. Peris and J. Bisquert, J. Phys. Chem. C, 2013, 117, 3826-3833.

61 F. F. Abdi and R. Van de Krol, J. Phys. Chem. C, 2012, 116, 9398-9404.

62 D. K. Zhong, S. Choi and D. R. Gamelin, J. Am. Chem. Soc., 2011, 133, 18370-18377.

63 R. Abe, M. Higashi and K. Domen, J. Am. Chem. Soc., 2010, 132, 11828-11829.

64 W. Kim, T. Tachikawa, D. Monllor-Satoca, H.-i. Kim, T. Majima and W. Choi, Energy Environ. Sci., 2013, 6, 3732-3739.

65 J. Wu, Y. Li, J. Kubota, K. Domen, M. Aagesen, T. Ward, A. Sanchez, R. Beanland, Y. Zhang, M. Tang, S. Hatch, A. Seeds and H. Liu, Nano Lett., 2014, 14, 2013-2018.

66 J. R. McKone, A. P. Pieterick, H. B. Gray and N. S. Lewis, J. Am. Chem. Soc., 2012, 135, 223-231.

67 M. J. Choi, J.-Y. Jung, M.-J. Park, J.-W. Song, J.-H. Lee and J. H. Bang, J. Mater. Chem. A, 2014, 2, 2928.

68 B. Klahr, S. Gimenez, F. Fabregat-Santiago, T. Hamann and J. Bisquert, J. Am. Chem. Soc., 2012, 134, 4294-4302.

69 M. Barroso, C. A. Mesa, S. R. Pendlebury, A. J. Cowan, T. Hisatomi, K. Sivula, M. Gratzel, D. R. Klug and J. R. Durrant, Proc. Natl. Acad. Sci. U. S. A., 2012, 109, 15640-15645.

70 C. Y. Cummings, F. Marken, L. M. Peter, A. A. Tahir and K. G. U. Wijayantha, Chem. Commun., 2012, 48, 2027-2029.

71 A. J. Bard, A. B. Bocarsly, F. R. F. Fan, E. G. Walton and M. S. Wrighton, J. Am. Chem. Soc., 1980, 102, 3671-3677.

72 E. McCafferty, in Introduction to Corrosion Science, Springer, New York, 2010, ch. 6, pp. 95-117.

73 A. J. Bard and M. S. Wrighton, J. Electrochem. Soc., 1977, 124, 1706-1710.

74 H. Gerischer, J. Electroanal. Chem. Interfacial Electrochem., 1977, 82, 133-143.

75 S. Chen and L.-W. Wang, Chem. Mater., 2012, 24, 36593666.

76 P. A. Kohl, S. N. Frank and A. J. Bard, J. Electrochem. Soc., 1977, 124, 225-229.

77 A. Kargar, K. Sun, Y. Jing, C. Choi, H. Jeong, G. Y. Jung, S. Jin and D. Wang, ACS Nano, 2013, 7, 9407-9415.

78 A. Kargar, K. Sun, Y. Jing, C. Choi, H. Jeong, Y. Zhou, K. Madsen, P. Naughton, S. Jin, G. Y. Jung and D. Wang, Nano Lett., 2013, 13, 3017-3022.

79 B. Seger, T. Pedersen, A. B. Laursen, P. C. K. Vesborg, O. Hansen and I. Chorkendorff, J. Am. Chem. Soc., 2013, 135, 1057-1064. 
80 Y. Lin, C. Battaglia, M. Boccard, M. Hettick, Z. Yu, C. Ballif, J. W. Ager and A. Javey, Nano Lett., 2013, 13, 5615-5618.

81 A. Paracchino, V. Laporte, K. Sivula, M. Grätzel and E. Thimsen, Nat. Mater., 2011, 10, 456-461.

82 Z. Zhang, R. Dua, L. Zhang, H. Zhu, H. Zhang and P. Wang, ACS Nano, 2013, 7, 1709-1717.

83 P. Nikolaychuk, Silicon, 2014, 1-8.

84 M. Pourbaix, Atlas of Electrochemical Equilibria in Aqueous Solutions, Pergamon Press, London, 1966.

85 F. R. F. Fan, R. G. Keil and A. J. Bard, J. Am. Chem. Soc., 1983, 105, 220-224.

86 A. T. Howe, R. T. Hawkins and T. H. Fleisch, J. Electrochem. Soc., 1986, 133, 1369-1375.

87 F. Gstrein, D. J. Michalak, D. W. Knapp and N. S. Lewis, J. Phys. Chem. C, 2007, 111, 8120-8127.

88 E. W. Cowell, N. Alimardani, C. C. Knutson, J. F. Conley, D. A. Keszler, B. J. Gibbons and J. F. Wager, Adv. Mater., 2011, 23, 74-78.

89 G. Campet, J. P. Manaud, C. Puprichitkun, Z. W. Sun and P. Salvador, Act. Passive Electron. Compon., 1989, 13, 175189.

90 A. G. Aberle, Prog. Photovoltaics, 2000, 8, 473-487.

91 N. C. Strandwitz, D. J. Comstock, R. L. Grimm, A. C. Nichols-Nielander, J. Elam and N. S. Lewis, J. Phys. Chem. C, 2013, 117, 4931-4936.
92 K. Sun, X. Pang, S. Shen, X. Qian, J. S. Cheung and D. Wang, Nano Lett., 2013, 13, 2064-2072.

93 K. Sun, N. Park, Z. Sun, J. Zhou, J. Wang, X. Pang, S. Shen, S. Y. Noh, Y. Jing, S. Jin, P. K. L. Yu and D. Wang, Energy Environ. Sci., 2012, 5, 7872-7877.

94 M. Higashi, K. Domen and R. Abe, J. Am. Chem. Soc., 2012, 134, 6968-6971.

95 M. Liao, J. Feng, W. Luo, Z. Wang, J. Zhang, Z. Li, T. Yu and Z. Zou, Adv. Funct. Mater., 2012, 22, 3066-3074.

96 C.-Y. Lin, Y.-H. Lai, D. Mersch and E. Reisner, Chem. Sci., 2012, 3, 3482-3487.

97 M. Moriya, T. Minegishi, H. Kumagai, M. Katayama, J. Kubota and K. Domen, J. Am. Chem. Soc., 2013, 135, 3733-3735.

98 M. Seol, J. W. Jang, S. Cho, J. S. Lee and K. Yong, Chem. Mater., 2012, 25, 184-189.

99 D. R. Gamelin, Nat. Chem., 2012, 4, 965-967.

100 A. J. Cowan, C. J. Barnett, S. R. Pendlebury, M. Barroso, K. Sivula, M. Gratzel, J. R. Durrant and D. R. Klug, J. Am. Chem. Soc., 2011, 133, 10134-10140.

101 C. Du, X. Yang, M. T. Mayer, H. Hoyt, J. Xie, G. McMahon, G. Bischoping and D. Wang, Angew. Chem., Int. Ed., 2013, 52, 12692-12695.

102 J. Xie, X. Yang, B. Han, Y. Shao-Horn and D. Wang, ACS Nano, 2013, 7, 6337-6345. 